\title{
Ciclos de terças em certas canções da música popular no Brasil
}

\author{
Sérgio Paulo Ribeiro de Freitas (UDESC, Florianópolis, SC) \\ c2sprf@udesc.br
}

\begin{abstract}
Resumo: Com as transformações que marcam a história artística e teórica da tonalidade harmônica, os planos tonais que

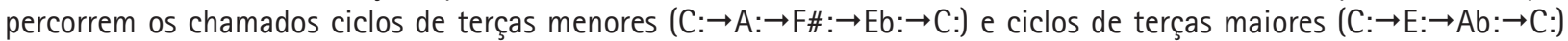
tornaram-se uma solução de expansão e renovação que afetou a composição musical em diversos gêneros e estilos. Estudando o emprego destes planos simétricos em canções produzidas no Brasil na segunda metade do século XX, este texto procura observar como tais escolhas podem ser impactantes na valoração de obras e artistas em determinado campo da música popular.
\end{abstract}

Palavras-Chave: Ciclos de terceira; plano tonal; teoria e crítica da música popular.

\section{Cycles of thirds in certain songs of popular music in Brazil}

Abstract: Due to the changes that characterize the history of art and theory of harmonic tonality, tonal plans that cover the so-called cycles of minor thirds ( $C: \rightarrow A: \rightarrow F \#: \rightarrow E b: \rightarrow C:$ ) and cycles of major thirds ( $C: \rightarrow E: \rightarrow A b: \rightarrow C:$ ) have become an expansion and renovation solution that affected different genres and styles of music. By studying the use of these symmetrical plans in Brazilian songs from the second half of the twentieth century, this paper attempts to shed light on how such choices can have an impact on the valuation of works and artists in the field of popular music.

Keywords: Cycles of thirds; tonal plan; theory and criticism of popular music.

\section{1 - Introdução}

Uma das temáticas envolvidas no estudo da música popular diz respeito ao reconhecimento daquilo que é posto junto, ou composto, em uma canção. As competências em reconhecer referências, e também a inevitável possibilidade de não percebê-las ou de desconhecê-las, conformam circunstâncias que apuram ou deturpam nossa apreciação valorativa quando lidamos com questões de autenticidade, originalidade ou reprodução, de criação de algo novo a partir de obras pré-existentes, de adaptação, empréstimo, citação ou rearranjo de outras fontes, de produção através da mistura ou fusão de elementos diversos etc. Assim, tal reconhecer é uma consabida condição analítica, um pré-requisito complexo que, direta ou indiretamente, está embutido em todo um vocabulário crítico, consideravelmente usual, onde se encontram noções-chave como: "apropriação", "bricolagem", "colagem", "guerrilha semiótica", "hibridismo", "rapinagem", "recontextualização", "relações interpoéticas", "releitura", "ressignificação", "sincretismo", "trabalho intertextual" (cf. SHUKER, 1999).
Neste amplo campo avaliativo, o presente texto destaca o conhecido argumento de que, dentro de certos limites, levar em conta o traçado dos planos tonais pode contribuir para tal reconhecimento de referências realçando aspectos e interações, nem sempre evidentes, que deixam transparecer como diferentes músicas tomam parte de uma espécie de conversa de longa data onde vários harmonistas participam escutando, re-escutando, dizendo e re-dizendo. 0 estudo dos planos tonais pode indicar que certas canções configuram-se como um tipo de criação que zela por um reter, um conservar, um repetir que se combina com um modificar aos poucos e com os outros. Não se trata então de um romper, de um inventar do nada, de um ato criativo autônomo que almeja fazer o que nunca se fez. Voltando a percorrer trajetos costumeiros, tais canções parecem dizer que importa conviver, assumir o contágio e o pertencer, importa transformar, o tomar para si, o comparar e o ser comparado. Em suma, a consideração dos planos tonais auxilia ouvir interlocuções musicais favorecendo 
a compreensão de que determinadas composições são soluções de reinvenção que, além dos sons propriamente ditos, em diferentes medidas e de diferentes maneiras, levam em conta algo das muitas memórias que estão prématuradas na vasta cultura da tonalidade harmônica.

Para reexpor sinteticamente a noção de "plano tonal", parafraseando SCHOENBERG (2001, p.410), digamos que, sob aspecto limitado, podemos compreender a harmonia de "toda composição como uma cadência mais ou menos extensa e rica, cujas mínimas partes integrantes não seriam cada um dos acordes, mas sim os acordes de conclusões parciais", os acordes de chegada, "colocados no ponto-chave de cada segmento de forma". Se estiverem "ordenados" segundo determinados critérios e valores, estes lugares de chegada dispostos um após outro delineiam uma espécie de "grande cadência": o chamado plano tonal.

A metáfora do plano tonal procura então representar, em uma imagem teórica, o alinhavo que demarca o prosseguimento das mudanças dos lugares de chegada (acordes, áreas tonais e tonalidades) ao longo de uma obra musical. Aproximando-se daquilo que CAPLIN (1998, p.195) chamou de "overall tonal organization", tal plano é um expediente técnico analítico que atende uma demanda artística, afetiva e comunicacional, pois "o fato [...] é que nossa sensibilidade auditiva reage diante das mudanças de regiões acústicas" (BARCE, 1978, p.19). Barce chamou esta arte da combinação das sonoridades em grande escala de "sistema de contraste entre regiões acústicas". A ideia é que, uma vez estabelecida uma tonalidade, o harmonizador passa a trabalhar com uma espécie de "corpo elástico, capaz de distender-se e de contrair-se em todas as direções". Do manejo criativo desse corpo elástico resultam diferentes relações sonoras que ajudam a compor diversificados efeitos expressivos.

Na música clássica e romântica, o plano tonal de uma composição consistia em sistematizar a variedade e a tensão construtivas graças a troca planificada de níveis acústicos e de modificações da escala. Nas composições breves, isso se conseguia com ligeiros deslocamentos tonais ou com um forte contraste tonal para logo voltar a tonalidade inicial. Nas composições extensas, o plano tonal podia chegar a ser muito complexo e significava um verdadeiro esforço criador (BARCE, 1978, p.19-20).

0 termo correlato "lugar de chegada" procura representar a concepção geral de que as escolhas e combinações dos acordes e áreas tonais se fazem por meio de dois comportamentos, vontades de construção ou funções complementares e essencialmente distintas. Alguns acordes ou áreas tonais cumprem o papel de meta, o ponto de mira que se procura atingir, o objetivo, a finalidade, o princípio e o fim. E outros são meios, aquelas harmonias que possibilitam a preparação e o alcance da meta, os passos que nos tiram de um estado de repouso e nos dirigem a um determinado fim. Diversas analogias, mais ou menos usuais, expressam essa dualidade que, ao mesmo tempo, é simples e complexa, abstrata e concreta: alguns acordes cumprem o papel de centro enquanto outros exercem atração ou são atraídos para tal centro. Alguns são de repouso e outros de movimento. Alguns são principais e outros secundários, sonoridades coadjuvantes que concorrem para um objetivo comum. Alguns são essenciais e outros são acessórios ou ornamentais. Alguns são da estrutura profunda e outros da estrutura de superfície. Então, a noção "lugar de chegada" (cf. FREITAS, 2010, p.393), grosso modo, equivale ao que é conhecido no campo da jazz theory como "target chord" (cf. RAWLINS e BAHHA, 2005, p.61). E, na teoria musical, como "meta tonal", "ponto de fechamento" ou "centro tonal" como diz MEYER (2000). Como "cadential goals" (CAPLIN, 1998, p.196) ou "acorde de descanso (Ruheklang)" nos termos de LA MOTTE (1993, p.275). E também como "acorde significante", aquele que "revela o sentido (significado)" e a "coerência tonal", aquele que, distinguindo-se do grupo dos "acordes gramaticais", "sublinha a especial intenção arquitetônica [...] dentro de uma frase" ou "seção de uma obra, ou de uma obra inteira" (SALZER, 1990, p.32). Neste sentido, o operador "lugar de chegada" correlaciona-se com noções schenkerianas conhecidas, tais como "prolongação harmônica" e "tonicização" (cf. FREITAS, 2010, p.380-385 e 403-405). E está claramente correlacionado ao âmbito conceitual daquilo que SCHOENBERG (2004, p.37) definiu através da metáfora espacial das "regiões" tonais (cf. DUDEQUE, 2005, p.101-110).

\section{2 - Ciclos de terceira: o elogio aos planos tonais estirados}

Dentre as tantas disposições dos lugares de chegada que podemos ouvir nos diversos repertórios da tonalidade harmônica moderna (grosso modo, séculos XVII e XVIII) e contemporânea (séculos XIX ao XXI), particularizamse aqui, em certas canções representativas da chamada "música popular brasileira", ou "MPB", dois planos tonais que se tornaram possiveis e conhecidos a partir da inclusão, tanto artística quanto teórica, das célebres "vizinhanças de terceira que envolvem transformações cromáticas" (KOPP, 2002). Ou mais especificamente, trataremos de canções em tonalidades maiores que, extrapolando os limites da "hierarquia tradicional dos tons vizinhos" (cf. FREITAS, 2010, p.389-390), valorizam as inovadoras relações de terceira (maior ou menor, abaixo ou acima) entre áreas tonais de modalidade maior que circunvizinham cromaticamente um I grau combinando os acordes (graus, regiões e/ou tonalidades) de bVI, VI, bIII e III. Então, tomando a tonalidade de Dó Maior como referência, observaremos escolhas que contrastam as regiões acústicas de Láb Maior (Ab:), Lá Maior (A:), Mib Maior (Eb:) e Mi Maior (E:).

A este grupo de áreas tonais prediletas acrescenta-se ainda a controversa área tonal que, provisoriamente, pode-se chamar de "submediante da submediante", ou seja, o lugar de chegada assentado no distante \#IV:, ou 
bV: conforme o caso. Na tonalidade de Dó Maior, o acorde ou área tonal de Fá\# Maior (F\#:) ou Solb Maior (Gb:). Área tonal que, estrategicamente, produz (reproduz) vizinhanças de terceira dos vizinhos de terceira de um I grau. Por fim, reorganiza-se este material em um desenho de círculo (Ex.1), uma representação que procura ancoragem na consagrada imagem teórica do ciclo de quintas. A partir deste dileto subconjunto (Ex.1a), dois pré-trajetos específicos se tornaram favoritos na reafirmação daqueles "três cânones gerais da Beleza: unidade, complexidade e intensidade" (NATTIEZ, 2005, p.13). Dois percursos simétricos, já que subdividem a oitava em três ou quatro partes equidistantes, conhecidos como: ciclo de terças menores (Ex.1b) e ciclo de terças maiores (Ex.1c).

Tais ciclos possuem uma considerável trajetória especulativa, já prenunciada por um Jean-Philippe Rameau (1682-1764) nos meados do século XVIII (cf. CHRISTENSEN, 1993, p.199; KOPP, 2002, p.33-37), e bastante desenvolvida por teóricos do século XIX, tais como Simon Sechter, Moritz Hauptmann, RimskyKorsakov e Hugo Riemann que são referenciados a seguir. As harmonias destes ciclos também carregam consigo alguns epítetos que sintetizam algo de sua valorosa presença na cena musical moderna e contemporânea. Em 1920, o musicólogo suiço Ernest KURTH (2005, p.178) caracterizou o romantismo como "das Zeitalter der Terzen" (a idade das terças). Em 1931, o compositor e teórico alemão Sigfrid KARG-ELERT (2007, p.203) propôs o termo "Mediantenstil" (estilo-mediante) para descrever "o estilo altamente cromático" de obras dos finais do século XIX. Em 1958, o musicólogo austro estadunidense Hans TISCHLER (1958) caracterizou as "mediantes cromáticas" como "a face musical do romantismo". E, para um musicólogo atual, como BRIBITZER-STULL (2006a, p.167), tais vizinhanças "são intrínsecas à música da Europa Central [...], o complexo Ab-C-E [o ciclo de terças maiores] é um protótipo da era romântica - uma marca

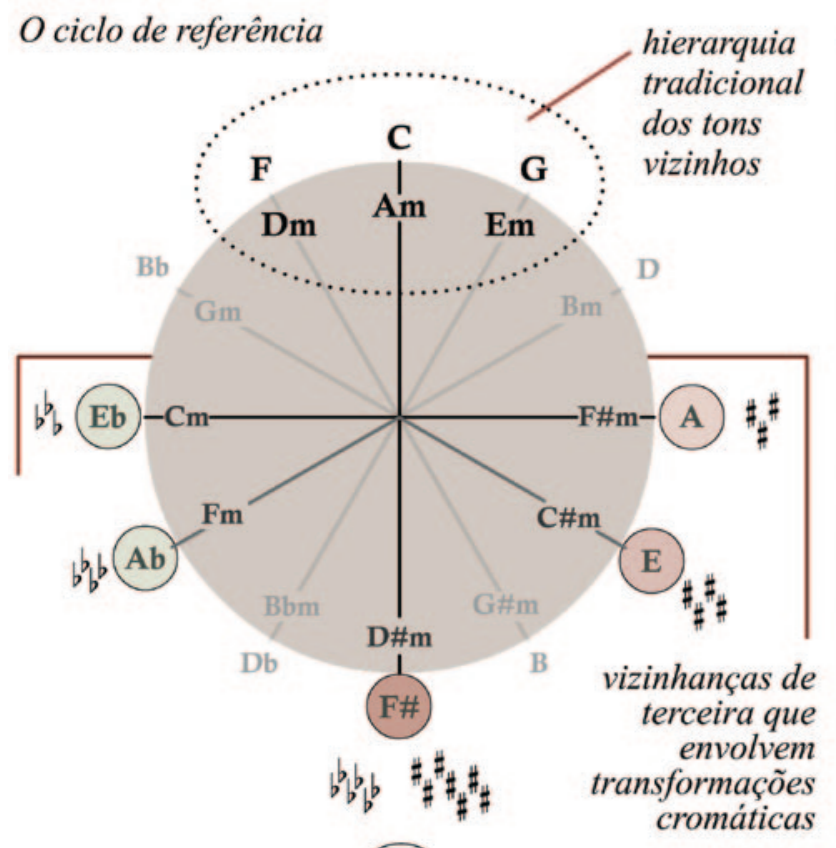

\section{a) Vizinhanças de terceira que envolvem transformações cromáticas}
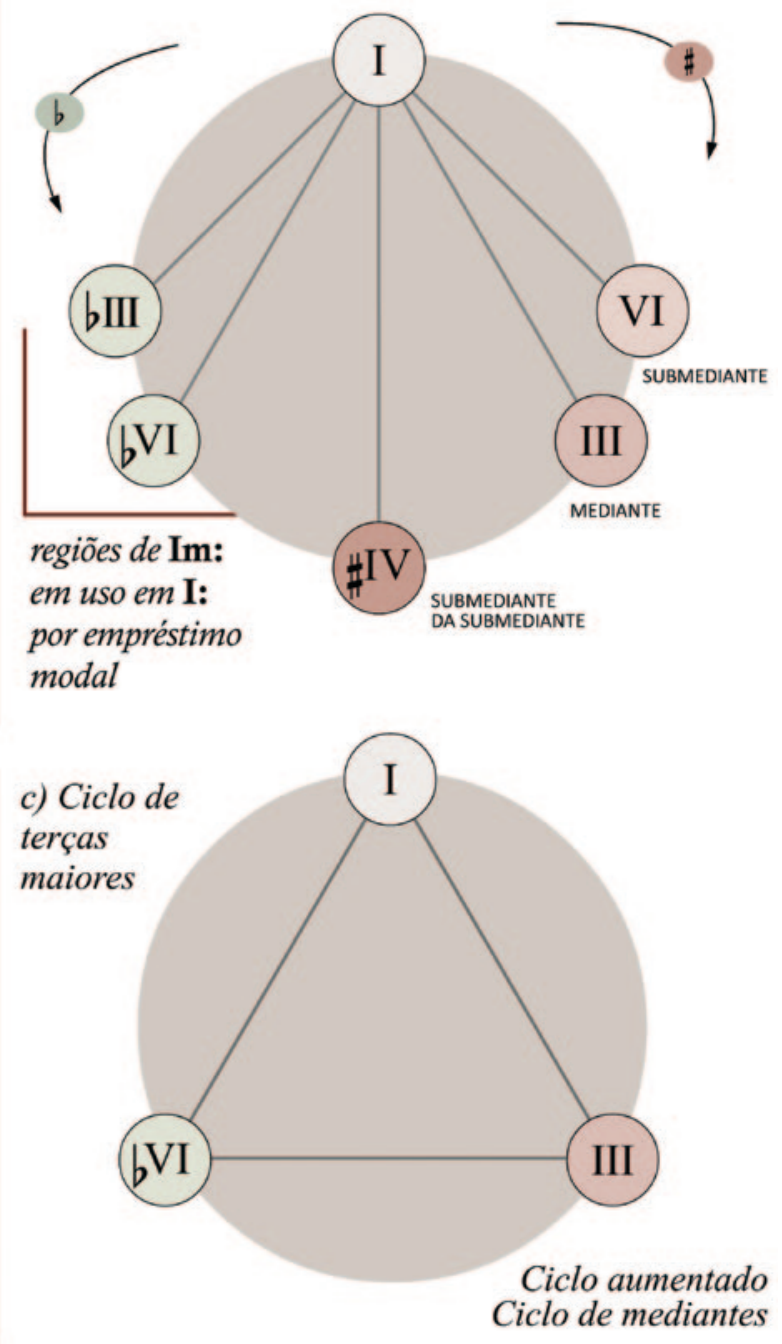

Ex.1 - Ciclos de terceira entre áreas tonais (acordes, regiões ou tonalidades) maiores 
de referência tanto para as orientações estruturais quanto para as tendências expressivas da música do século XIX".

Com tais trabalhos, mais antigos e mais recentes, passamos a contar com um vasto corpo de estudos que se fazem acompanhar de amplos levantamentos de obras - da lavra de compositores como Mozart, Beethoven, Schubert, Schumann, Chopin, Liszt, Brahms, Wagner, Rossini, Glinka, Korsakov, Dvořák, Bruckner, Wolf, Debussy, Prokofiev etc. - que empregam tais ciclos (cf. ALDWELL e SCHACHTER, 1989, p.545-546, 571-572; BASS, 1996, p.272; BRIBITZER-STULL, 2006a, p.174175, 180-186; CINNAMON, 1986, p.6-12; COHN, 2000, p.99-100; GAULDIN, 2009, p.534-542, 631-645; GOLLIN, 2000, p.38-42, 242-244, 290-293; JAVIER. 2009, p.300324; KINDERMAN e KREBS, 1996, p.17-33; KOPP, 2002, p.230-234; KREBS, 1980, p.28-29; LERDAHL, 2001, p.89104; MORGAN, 1976, p.60-61; OTTMAN, 2000, p.341342; PROCTOR, 1978, p.170-179, 198-200; ROSEN, 2000, p.358-360; SALZER e SHACHTER, 1999, p.182-188, 190191; SCHENKER, 1956, p.53; SCHOENBERG, 2004, p.162163; TARUSKIN, 1985; 1996, p.265-267, 280-283; TODD, 1988, p.111-112). E no campo da jazz theory, estes ciclos simétricos também são estudados por diversos autores (cf. BOLING e COKER, 1993, p.16-17; DELAMONT, 1965, p.269-275; HERRERA, 1995, p.117-121; MANGUEIRA, 2006, p.72-73; NETTLES e GRAF, 1997, p.162-165; STRUNK, 1999, p.259-260; 2008, p.329). Contudo, contando com as demais referências citadas ao longo deste texto, e levando em conta os esforços anteriores (cf. FREITAS, 2010), essa rica temática da teoria e arte musical ocidental (i.e., o patrimônio dos ciclos de terceira e suas histórias, detalhamentos técnicos, desdobramentos etc.), não será pormenorizadamente revista aqui.

\section{3 - Ciclos de terças menores: o caso do Hino ao Sol}

Dentre as canções da música popular produzida no Brasil que, em diferentes medidas, refazem o trajeto do ciclo de terças menores, destaca-se o Hino ao Sol. Um samba canção lento, uma espécie de arioso datado de 1954 que foi número da operística Rio de Janeiro - A montanha, o sol e o mar: Suite popular em tempo de samba. A concepção geral desta vultosa obra, conhecida hoje como Sinfonia do Rio de Janeiro, foi iniciativa do arquiteto, escritor e músico paraense William Blanco Abrunhosa Trindade, o Billy Blanco (1924-2011), em coautoria com o não ainda célebre Antônio Carlos Brasileiro de Almeida Jobim (1927-1994). Em Mib Maior em sua primeira gravação (Continental, LP-1.000-A), a faixa Hino ao Sol contou com a voz abaritonada do pianista e compositor carioca Farnésio Dutra e Silva, o Dick Farney (1921-1987), e também com arranjo e orquestração do já então bastante prestigiado maestro, pianista e compositor gaúcho Radamés Gnattali (1906-1988). Em artigo de 1960, o Hino ao Sol foi avaliado como uma canção antecipadora da bossanova (BRITO, 1986, p.20) e, conservando algo deste valor, vem sendo recriado (cf. NASCIMENTO, 2008, p.134-135), re-estudado por sua "modernidade musical" (POLETTO, 2004 p.15-16, 106108), e analiticamente interpretado como etapa de um "caminho para a construção de uma nova linguagem musical" (KUEHN, 2004, p.132-142). Considerando tais trabalhos, é possível ainda destacar que, na produção desta canção persiste uma sorte de efeito residual, mesmo que sutil e chistoso, daquele prodigioso fenômeno contemporâneo e internacional que, em ensaio de 1924, o poeta musicólogo Mário de ANDRADE (1963, p.52) caracterizou como "wagnerofilia".

A fecundidade perdurante desse "amor à Wagner", dessa devoção pelas soluções musicais associadas ao nome do compositor alemão Richard Wagner (1813-1883), pode ser uma recuperação de certo interesse no conjunto das apreciações ao Hino ao Sol. Pois, a sua maneira - seja pela escolha da singular harmonia que em apenas oito compassos percorre quase todo um ciclo de terças menores (Ex.2), seja pelas altissonantes soluções de timbre e orquestração (que não serão comentadas na presente oportunidade), ou seja pelo emprego de expressões literais como "eu quero morrer [...] na plenitude da vida" -, o Hino ao Sol reinventa traços daquele trágico "morrer de amor" que se ouve na ária final de Tristan und Isolde, o drama musical escrito por Wagner entre aproximadamente 1856-60.

Tal ária (Mild und leise, $3^{\circ}$ ato, a partir do c.1621) é conhecida como Liebestod (literalmente amor-morte, a morte de amor, o amor através da morte, o morrer de amor), ou Verklärung (transfiguração) como Wagner preferia chamá-la (cf. BAILEY, 1985, p.41-43). Como se sabe, consubstanciando a interrelação entre vários pontos do drama, a Liebestod ressoa quando, após prodigiosa saga, Tristão já não mais respira "e Isolda, ao chegar e vêlo morto, estende-se sobre ele, rosto com rosto, boca com boca, e nesse abraço expira e morre" (WISNIK, 1987, p.207). "Essa morte por amor [...] propiciadora de sua união final, [...] simboliza a assimilação pela natureza de tudo o que é espiritual, e portanto imortal, nas vidas iluminadas pelo amor" (KOBBÉ, 1991, p.160). A cena é de uma dor infinita e, numa espécie de moral da história, a sublimação da paixão deve nos persuadir de sua força edificante e expiatória. A intensidade em cena exige um composto total - em uma obra de arte total ou integral - sublime e incomum, um tratamento de tirar fôlego em todos os âmbitos. ${ }^{1}$ Exige uma harmonia igualmente transfigurada e adúltera, posto que o idílio de amor de Tristão e Isolda já foi visto como o "grande mito europeu do adultério" (Rougemont, citado por WISNIK, 1987, p.207).

Nos compassos iniciais da Liebestod podemos ouvir, contando com alguns estudos prévios (ABROMONT e MONTALEMBERT, 2010, p.200-201; MEYER, 2000, p.459464; RATNER, 1992, p.182-185; SCHOENBERG, 2004, p.154 e 156), um percurso por terças menores similar ao que vamos reouvir nos compassos iniciais do Hino ao Sol. Só que aqui, associado ao cenário tropical num gesto matreiro e bem humorado, é preciso notar que o ciclo gira em sentido horário. Ou seja, em sentido inverso ao 


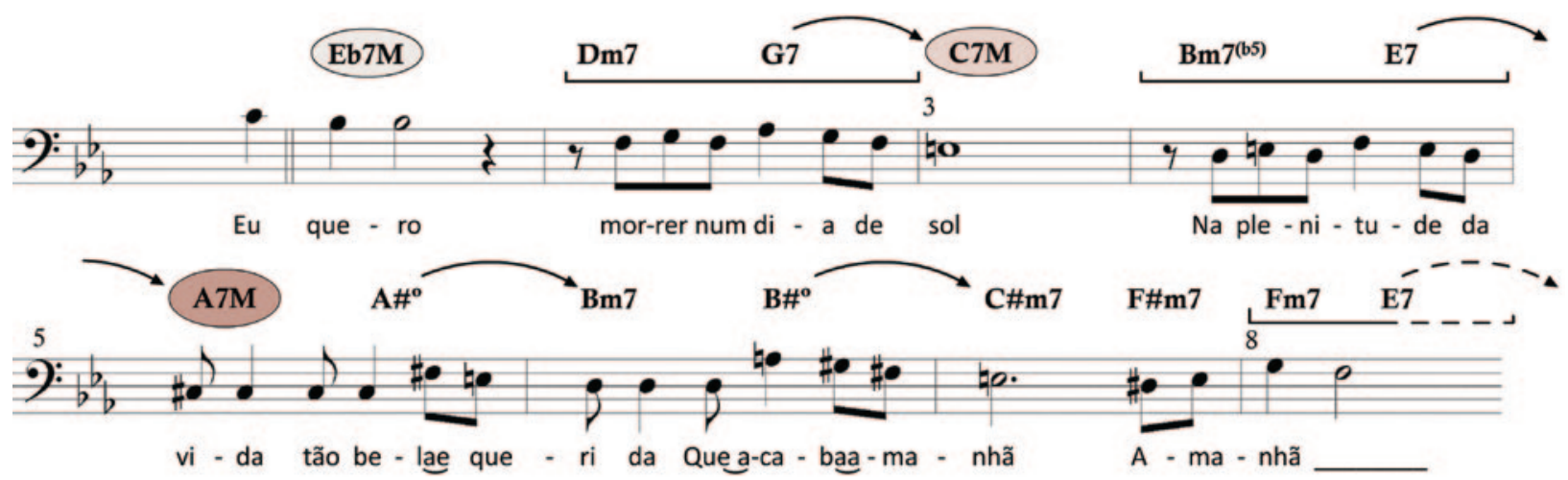

Eb:

$3 \quad 5$

5
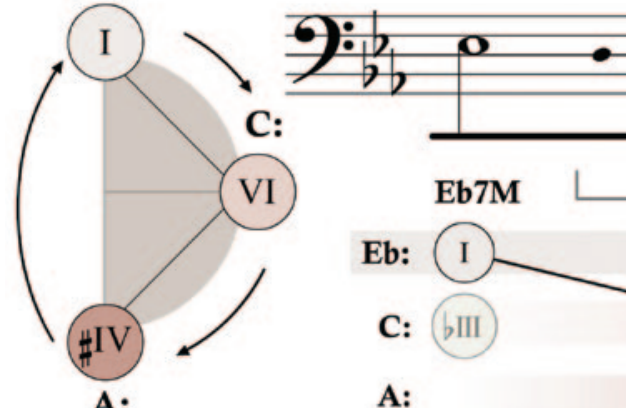

A:

Ex.2 - 0 incompleto ciclo de terças menores no Hino ao Sol de Billy Blanco e Tom Jobim, 1954

pesaroso círculo posto a rodar na cena final de Tristan und Isolde. Somando-se aos costumes pré-modernos, modernos e contemporâneos que, entre outros diversos hábitos musicais, nos ensinam a adequar as coisas alegres e otimistas ao modo maior e, de contrário, os textos, assuntos, ocasiões e afeições tristes e acabrunhadas ao modo menor (cf. MEYER, 2001, p.230-235), o sentido de rotação do ciclo é mais uma das influentes associações entre sons, humores e imagens cultivadas ao longo da história da tonalidade harmônica. 0 sentido anti-horário do "Kleinterzzirkel" Ab: $\rightarrow \mathrm{Cb}: \rightarrow \mathrm{D}: \rightarrow \mathrm{F}$ : escolhido por Wagner depende da aparição de mais bemóis, e caminhar nesta direção estimula associações com a chamada ambientação "flatness" (cf. CHAFE, 2000, p.148) vinculada ao sombrio, ao noturnal, ao introspectivo, ao entristecido e ao patético. Já a escolha que ouvimos no Hino ao Sol, progredido pelo lado "sharpness", conta com a aparição de sustenidos numa trilha de tonicizações periodicamente espaçadas, Eb: $\rightarrow C: \rightarrow A$ :, sugerindo vinculações com o jubiloso, a luminozidade, a claridade, a evidência e a positividade.

Ademais, como se sabe, o ciclo de terças menores aparece em outras cenas de Tristan und Isolde (cf. KOPP, 2002, p.221-224; LERDAHL, 2001, p.115-119; PISTON, 1993, p.456-457; SCRUTON, 1999, p.273-274). E aparece em outros dramas musicais de Wagner. Posto tal legado artístico, é oportuno considerar que, entrementes, algo do valor associado ao tão singular mapa de acordes se deve também aos esforços especulativos de vários estudiosos, incluindo ai os controversos textos do próprio Wagner. Veja-se o caso: na parte final de seu ensaio Über die Anwendung der Musik auf das Drama (sobre a aplicação da música no drama) publicado em 1879, Wagner destaca justamente uma de suas elaborações sobre este ciclo (cf. TARASTI, 2002, p.35-37). Trata-se de um ciclo de terças menores de Lohengrin. No primeiro ato deste drama musical, escrito entre 1846-47, também em apenas oito compassos, o expandido trajeto $\mathrm{Ab}: \rightarrow \mathrm{Cb}: \rightarrow \mathrm{D}: \rightarrow \mathrm{F}: \rightarrow \mathrm{Ab}$ : ambienta uma passagem da ária Einsam in trüben Tagen (sozinha nos dias sombrios), ou Elsa's Traum (o sonho de Elsa). As interpretações analíticas desta passagem especifica se tornaram consideravelmente estimadas $e_{\text {, }}$ contando com os destaques apresentados por teóricos do porte de SCHOENBERG (2004, p.127), nos acompanham até os dias de hoje (cf. DUDEQUE, 1997, p.131-132; DUNSBY e WHITTALL, 2011, p.105-106; FREITAS, 2010, p.253-258; KARG-ELERT, 2007, p.276-277). Com isso, e parafraseando comentários que GREY (in MILLINGTON, 1995, p.263) faz ao léxico dramático musical wagneriano, pode-se observar que, também aqui (Ex.2), nesta espécie de retrato cantado daquela que, à época, era a capital federal da nossa "terra de samba e pandeiro", reencontramos escolhas acórdicas simétricas sonorizando o impulso retórico das unidades poético verbais. Reencontramos a estratégia de unificação, de correlação assonante, entre o lirismo descritivo, a cambiante expressão narrativa e as persuasivas mutações harmônicas por entre regiões tonais distantes (cf. FREITAS, 2010, p.739-743). ${ }^{2}$ 
Neste segmento do Hino ao Sol (Ex.2), que musicalmente é basicamente o mesmo para a primeira e segunda estrofes, a não aparição do lugar de chegada blll (Gb:) reclama um passo abreviado que também possui determinadas memórias românticas, tantoartísticasquanto especulativas. A saber: a trilha $\mathrm{Eb}: \rightarrow \mathrm{C}: \rightarrow \mathrm{A}: \rightarrow \mathrm{Gb}: \rightarrow$ Eb: está condensada como Eb: $\rightarrow \mathrm{C}: \rightarrow \mathrm{A}: \rightarrow$ Eb:. $\mathrm{E}$ tal abreviação evidencia a estirada e controversa relação de trítono, $A: \rightarrow E b:$ nos contra pólos de um meio ciclo de terças menores. Esta relação antípoda, aqui entre \#IV $\rightarrow \mid$, foi, e em alguma medida continua sendo, particularmente controversa na história da tonalidade harmônica (cf. BROWN, DEMPSTER e HEADLAM, 1997; DAMSCHRODER, 2008, p.224-230). Uma de suas memórias mais emblemáticas data dos anos de 1830, quando os tais enlaces por tritono repercutiram em certas passagens da Symphonie Fantastique do compositor romântico francês Hector Berlioz (18031869). As escolhas musicais do "enfant sauvage" Berlioz contribuíram para que a Fantastique fosse "aclamada pela juventude romântica" (SOLEIL e LELONG, 1992, p.150), enquanto que o seu "duvidoso valor harmônico" estimulou inolvidáveis polêmicas, particularmente amplificadas pela crítica publicada em 1835 pelo compositor alemão Robert Schumann (1810-1856).

Este caso da Symphonie Fantastique é bem conhecido e não será novamente estudado aqui (cf. BENT, 2004, p.161194; FREITAS, 2010, p.753-754; ROSEN, 2000, p.715750; SCHENKER, 1990, p.172-173). Mas, ainda assim, a menção importa para realçar algo do capital simbólico acumulado pela opção de se tratar como vizinhos estes lugares de chegada extremamente distantes. Vale dizer: nas entrelinhas da escolha \#IV $\rightarrow \mid$ se inscrevem traços de uma cultivada rebeldia romântica, traços de ímpeto e inconformismo, de intensidade e complexidade, de libertação do julgo externo e do fardo imposto pela tradição. Vestígios de uma vigorosa e revigorante indisciplina juvenil. $E$, principalmente, de uma reafirmação do sublime ideal romântico da "representação da natureza em toda a sua assombrosa diversidade" (MEYER, 2000, p.282).

No caso aqui em apreço, do nosso romântico, popular e laudatório Hino ao Sol, e logo após alguns versos de introdução e demarcação local e autobiográfica ("Rio de janeiro / que eu sempre hei de amar"), o impulso "sharpness" Eb: $\rightarrow$ C: $\rightarrow$ A: arrematado pelo emblemático, infracionário e supranatural movimento $A: \rightarrow E b:$ conforma um roteiro tonal concentrado, breve e potente. Eficiente na harmonização das belezas grandiosas e enlevadas que, desvelando o eu do poeta, são versificadas em imagens estereotipadas como: "eu sempre hei de amar", "num raio claro de sol", "na plenitude da vida", "a cada amanhã", "quem sabe eu voltarei", "natureza sem par", "a montanha, o céu e o mar".

Tais fragmentos do texto reforçam que as recriações aqui ultrapassam o âmbito do plano tonal. Desde o título, a canção se apresenta como obra intertextual. Como se sabe, a poderosa metáfora do sol se faz presente em culturas diversas e, na tradição grecolatino-cristã, na qual a arcaica mística solar às vezes se acha entremesclada aos assuntos da teoria musical (cf. FREITAS, 2010, p.557-558), alguns textos em louvor ao sol gozam de alto prestígio. Textos clássicos como o Hino Homérico a Hélio (personificação do sol), o Hino a Hélio de Juliano, o Apóstata (331-363), e o Hino ao Sol de Proclo Lício (412-485). E temos também os hinos a Apolo, o "deus da música" que foi igualmente associado ao sol. Dentre os atributos comentados por RIBEIRO JR (2010, p.372-381), o sol é o "incansável", aquele que, sem jamais deter seu ciclo, de dia se desloca do nascente ao poente e de noite vaga pelo dorso do mundo até reencontrar o oriente. Então, os fugidios lugares do ciclo $E b: \rightarrow C: \rightarrow A: \rightarrow E b:$, se mostram como escolhas sugestivas para retratar em acordes o inexorável fato de que não podemos olhar o sol durante muito tempo. Restam-nos as olhadelas e com isso apreender que o sol não se estanca em um só lugar.

Transpassando marcos da hinografia culta e também o universo wagneriano, pode-se ainda notar que, esta opção pelo ciclo de terças menores em composições que fazem apologia aos lugares e naturezas é encontrada, em medidas e soluções diferentes, em outros repertórios das músicas populares que, direta ou indiretamente, dialogam com este modernizador Hino ao Sol carioca. Vejam-se os seguintes dois casos.

Uma ocorrência internacional próxima e representativa, datada de 1941, é a exitosa canção I'll Remember April com música de Gene de Paul e versos de Patricia Johnston e Don Raye. Uma produção musical estadunidense, oriunda do rentoso estágio da indústria de entretenimento genericamente conhecido como Tin Pan Alley (cf. FORTE, 1995; FREITAS, 2010, p.600-624; SCHUKER, 1999, p.280). Em versões diversas, com ou sem letra, I'll Remember April foi gravada por artistas de renome mundial, tais como Woody Herman, Nat King Cole, Ann Miller, Doris Day, Judy Garland, Stan Kenton, Frank Sinatra etc. Foi ouvida em sucessos cinematográficos da década de 1940, tais como Ride 'em Cowboy, Strictly in the Groove e Eve Knew Her Apples. E, pelas mãos de personagens como Bud Powell, Charles Mingus, Charlie Parker, Clifford Brown, George Shearing, Lionel Hampton e Sonny Rollins, converteu-se em um estimado Standard do repertório de jazz. Assim, tecnicamente reproduzidas, as imagens saudosas e primaveris de I'll Remember April, expressas em versos como "não temo o outono e sua tristeza [...] vou me lembrar de abril e sorrir", foram massivamente distribuídas e consumidas. $E$ tais imagens estão ambientadas por escolhas harmônicas que, contrastando os passos "flatness" $\mid \rightarrow$ blll e $\mathrm{VI} \rightarrow \mid$ com os contrapassos "sharpness" $\mid \rightarrow \mathrm{VI}$ e blll $\rightarrow \mid$, conformam um plano tonal que, a seu modo, também perpassa um incompleto ciclo de terças menores, $\mathrm{G}: \rightarrow \mathrm{Bb}: \rightarrow \mathrm{G}: \rightarrow \mathrm{E}: \rightarrow \mathrm{G}:($ Ex.3).

No tópico "centros tonais que se deslocam por terças menores", LEVINE (1995, p.366-367) comenta a 
combinação $B: \rightarrow D: \rightarrow A b: \rightarrow F: \rightarrow B:$ que se destaca nos dez compassos do plano tonal de outro benquisto cartão postal musical. 0 cenário agora é uma face do parque metropolitano, uma espécie de oásis verde, cultivado em meio ao distrito de Manhattan na cidade de Nova lorque. Trata-se de Central Park West (Ex.4), balada de autoria do saxofonista e compositor de jazz norte-americano John Coltrane (1926-1967), gravada em 1960 no álbum Coltrane's Sound (lançado em 1964 pela Atlantic Records). No campo da jazz theory, Central Park West é lembrada como uma espécie de estudo concentrado, uma exploração sistemática das chamadas capacidades "multitônicas dos ciclos de terceira" (cf. HERRERA, 1995, p.117-121; NETTLES e GRAF, 1997, p.162-165). ${ }^{3}$

Ainda que breves tais menções - aos residuos da "wagnerofilia", aos influxos da concepção Tin Pan Alley e ao prestígio dos experimentos de Coltrane são provisoriamente suficientes para ir adiante. Mas não sem antes ressalvar que, particularidades destas temáticas até aqui mencionadas relacionam-se com as canções comentadas a seguir. $E$ que, aspectos abordados a seguir são em parte contributivos na apreciação deste Hino ao Sol.

\section{4 - 0 caso do ciclo de terças menores em Setembro}

Fotografando outros cenários, momentos e personagens da indústria da MPB, é possível notar que os centros tonais que se deslocam por terceiras simétricas estão na base de outras bossas, mais novas, que também contribuíram, local e internacionalmente, para a consolidação de uma imagem de música "popular" e "brasileira". Vinte e tantos anos depois da aparição do Hino ao Sol, os parceiros Gilson Peranzzetta, Vitor Martins e Ivan Lins revisitam o notório percurso de terças menores em Setembro, composição gravada em Dó Maior e sem palavras no LP Ivan Lins, Novo Tempo (EMI) de 1980.

Importa logo esclarecer que não se trata de propor uma suposta sucessão causal, linear unívoca e coerente, coligando de maneira determinística os planos tonais supra e inframencionados aos acordes de Setembro. A trama da cultura tonal, como se sabe, é densa e tão entrelaçada que só pode ser fragmentadamente amostrada. As escolhas musicais de artistas como Gilson Peranzzetta e Ivan Lins e, grosso modo, dos harmonistas desta geração, direta ou indiretamente interagem continuamente com repertórios vastos que, por seu turno, também estão ativos e sofrendo

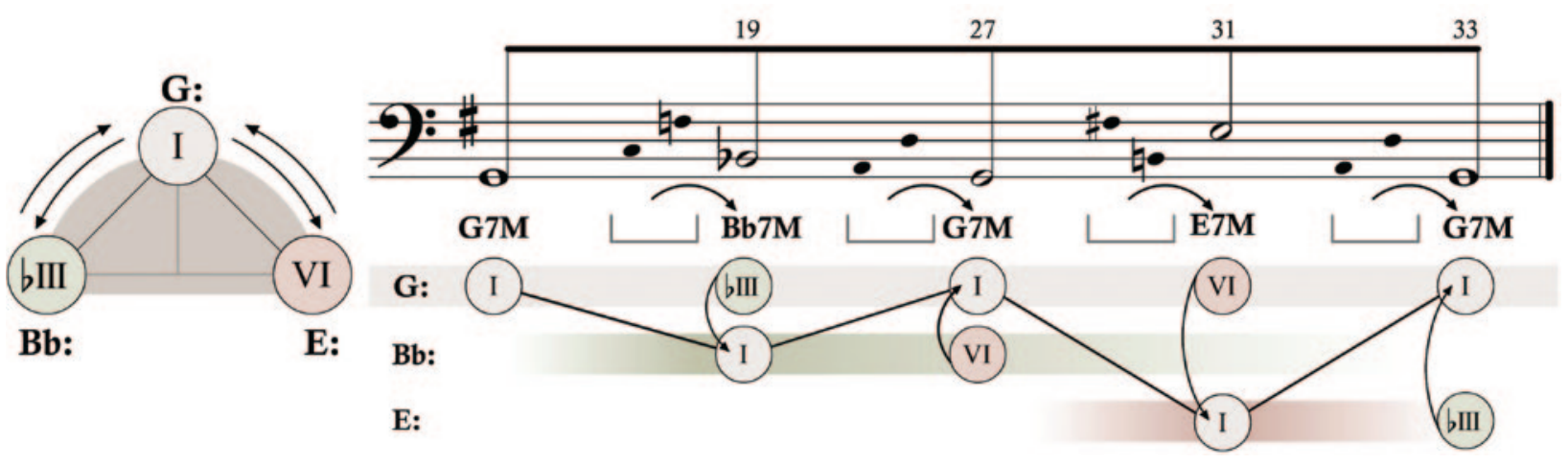

Ex.3 - 0 ciclo de terças menores em I'll Remember April de Gene de Paul, Patricia Johnston e Don Raye, 1941

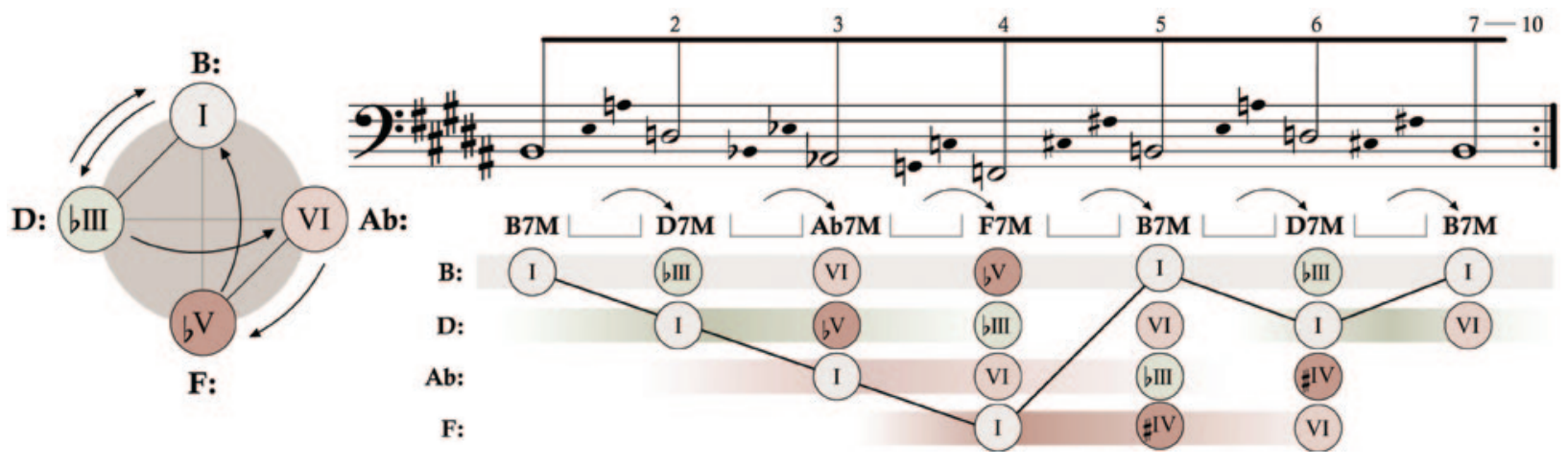

Ex.4 - 0 ciclo de terças menores em destaque no plano tonal de Central Park West de John Coltrane, 1960 
incessantes contaminações e comutações. Para ilustrar parcialmente a amplitude desta observação, podemos reouvir alguns casos jazzísticos que marcaram época reinventando ciclos de terças menores em composições como: Forest Flower de Charles Lloyd e Fly Little Bird Fly de Donald Byrd lançadas em 1966; Litha de Chick Corea lançada em 1967 e Hotel Vamp de Steve Swallow lançada em 1974.

Estudar planos tonais antecedentes, seja em obras oriundas deste repertório jazzístico dos anos de 196070 ou em sambas pré bossanova, seja em canções Tin pan Alley ou no vasto repertório erudito clássico e romântico, pode contribuir na apreciação das absorções e transformações criativas que ouvimos em Setembro. Mas convém também procurar pontos de contato com o campo especulativo. Os primeiros oito compassos da primeira parte de Setembro (Ex.5) percorrem o ciclo de terças menores $\mathrm{C}: \rightarrow \mathrm{A}: \rightarrow \mathrm{F \#}: \rightarrow \mathrm{Eb}:$ num encadeamento de contrastes harmônicos que parece seguir um roteiro prescrito bem antes, em 1853. Tal roteiro (Ex.6), uma espécie de rota de terças de picardia, já que se trata de um procedimento de reduplicação do molde "I $\rightarrow$ vi/VI", foi descrito pelo supracitado professor, compositor e teórico austríaco Simon Sechter (1788-1867).

Em se querendo percorrer mais rápido [ou atalhar] o círculo [de quintas] têm-se os seguintes recursos [ou meios]: Partindo de Dó Maior tome o caminho para Lá Menor, mas uma vez que você vem de uma Dominante, pare em Lá Maior. De lá pegue a estrada para Fá\#
Menor, mas pare em F\# Maior; depois de confundir (enarmonizar) F\# Maior com Gb Maior, tome o caminho para Eb Menor, mas conclua em Eb Maior; pegue o caminho para C Menor, mas conclua em C Maior, assim o circulo se fecha (SECHTER, 1853, p.205).

Insistindo um pouco mais na observação de que, estes planos tonais que ouvíamos em certas canções dos últimos anos do século $X X$ estão muito próximos e, ao mesmo tempo, muito distantes das teses dos harmonologistas austro-germânicos da geração romântica, podemos apreciar as escolhas de Setembro à luz de outros argumentos e instruções publicadas também em 1853, agora pelo supramencionado teórico, professor e compositor alemão Moritz Hauptmann (1792-1868), em um tratado já conceituado como "uma das mais importantes e valiosas obras sobre a harmonia que possuímos" (SHIRLAW, 1969, p.352). Abordando estas "relações cromáticas de terceira" em seu Die Natur der Harmonik und der Metrik: zur Theorie der Musik (cf. KOPP, 2002, p.51-60), Hauptmann não deixou de notar que, como se sabe, um dos desafios que se enfrenta na lida com essas harmonias simétricas é a condição de que, com tantos acidentes ocorrentes, não é fácil encaixar uma melodia "natural" aqui.

A engenhosa solução de Setembro parece tirar improvável proveito de uma sugestão de HAUPTMANN (1888, p.149150) que, em linhas gerais, prediz: tais "cadeias de terças" (menores ou maiores) devem estar "fundamentadas",

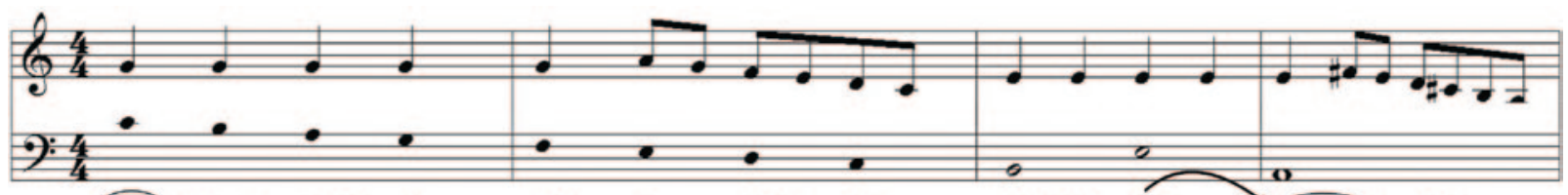

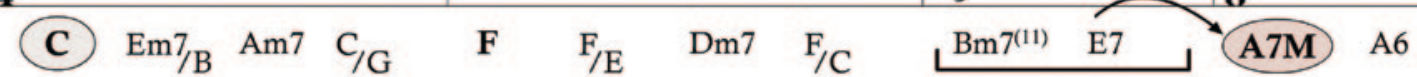
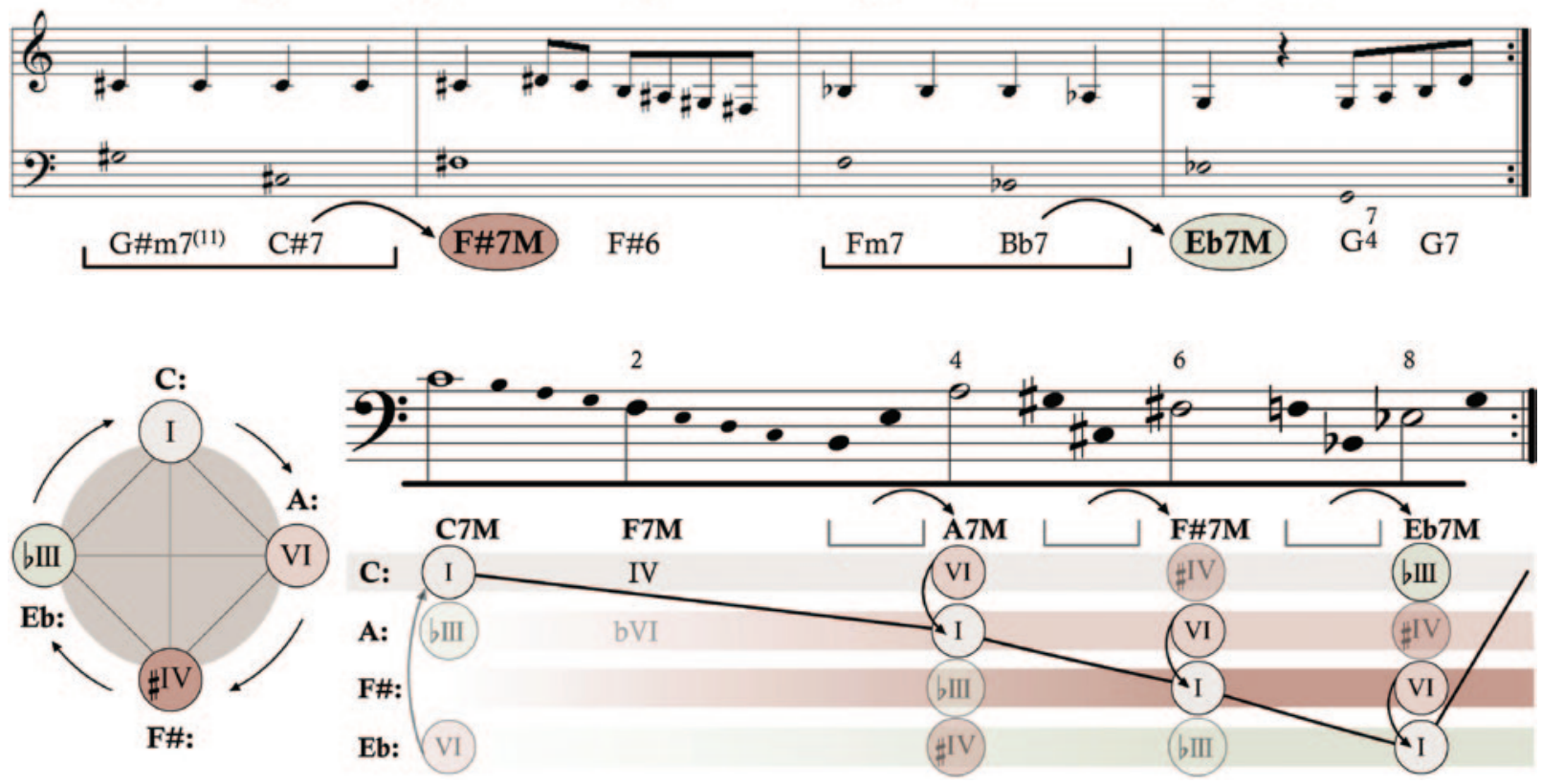

Ex.5 - 0 ciclo de terças menores em Setembro de Gilson Peranzzetta, Vitor Martins e Ivan Lins, 1980 


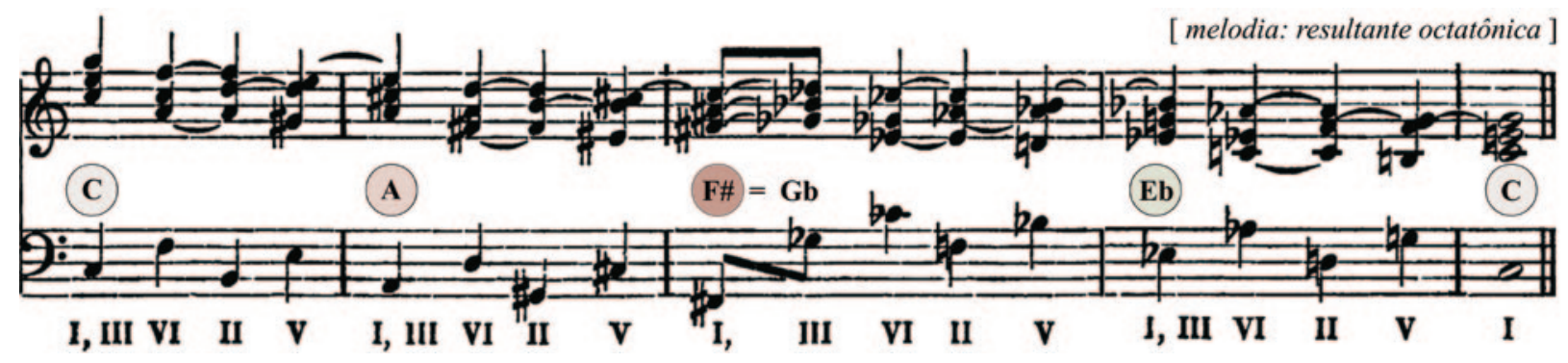

Ex.6 - 0 ciclo de terças menores na demonstração publicada por Sechter em 1853

ou progressivamente arranjadas "a partir das notas das tríades tônicas". Para tanto, uma das "notas naturais" (i.e., a fundamental, a terça ou a quinta) da tríade tônica do tom de saída deve ser reinterpretada como nota constitutiva da tríade tônica do novo tom (cf. FREITAS, 2010, p.239240). No caso do ciclo de terças menores, complementa Hauptmann, bom é "interpretar a terça como quinta".

E, com efeito, em Setembro, na provisória chegada em A7M (c.4), o VI grau, submediante de Dó Maior, a melodia canta a quinta, a nota Mi que foi terça de C7M, o I grau anterior. Na chegada em F\#7M (c.6), o distante \#IV, a submediante de Lá Maior, a melodia canta a nota Dó\#, a ex-terça de A7M. Por fim, na chegada em Eb7M (c.8), a região de blll de Dó Maior, a melodia alcança a terça, a nota Sol que foi e voltará a ser a quinta do tom principal (C:) para aonde a canção retorna e recomeça

Em diferentes versões, Setembro é conhecida pelos títulos, ou subtítulos, Brazilian Wedding Song e Amada. E sua letra, que ambientou o romance de Antônio e Fernanda na telenovela Meu bem, meu mal escrita por Cassiano Gabus Mendes e exibida pele Rede Globo entre 1990-91, entoa versos como: "Vai amada, mesmo a vida sendo perigosa [...] nunca queira desistir de um grande amor", "Há de ser ainda amada, [...] apesar de tudo que é feito, prá minar a paz de um grande amor". Então, mais uma vez, a escolha objetiva do ciclo de terças menores se ouve coligada aos subjetivos assuntos do amor, do casal, da infinitude da aliança. Em um hipotético exercício de "tonalidade associativa", pode ser sugestivo considerar que, talvez, o ciclo de Setembro gire em sentido "sharpness", $I \rightarrow V I$, justamente porque aqui, como ocorre com o Hino ao Sol, o amor é cantado como positividade, superação e felicidade. Enquanto que, como se sabe, nos dramas musicais de Wagner o movimento "flatness" $\mid \rightarrow$ blll intensifica a narrativa das vicissitudes e consternações dos casais Lohengrin e Elsa e Tristão e Isolda. ${ }^{4}$

Tais aspectos destacados até aqui oportunizam uma referência aos conhecidos comentários que SCHOENBERG (2004, p.126-133) nos deixou a respeito de "nove exemplos das óperas de Wagner". Schoenberg considera que, em princípio, tais exemplos "ilustram procedimentos não modulatórios". Ou seja, são casos de "monotonalidade" em situações complexas, já que neles "muitas mudanças essenciais" ocorrem em espaço de tempo muito abreviado. Schoenberg observa que, em determinados casos, a vertiginosa intensidade dessas situações está contraequilibrada pelo emprego de "sequências" e "quasesequências". Ou seja: as harmonias complexas estão contrabalançadas por repetições simples e periódicas de um modelo bem contrastado, i.e., um construto musical ou segmento padrão combinando contorno melódico, rítmico e harmônico, articulação, dinâmica, tessitura, registro, orquestração, rimas de texto etc., relativamente curto, memoriável e com algum "apelo popular". Tais construtos que se deslocam através de harmonias simétricas sem maiores elaborações, são uma espécie de variante sonora do mesmo que nos atraem condicionando a audição em situações de tonalidade "muito expandida". Tais "sequências" e "quase-sequências" atuam, por assim dizer, como tábuas de salvação, e seus resultados artísticos serão mais ou menos duvidosos a depender da dosagem das repetições, do compromisso artístico do harmonizador e da formação crítica do ouvinte. ${ }^{5}$

\section{5 - 0 caso do ciclo de terças menores em Sapato Velho}

Outro caso memorável que pode ilustrar o emprego do ciclo de terças menores em hits desta época da MPB é o da canção Sapato Velho de autoria de Mú Carvalho, Cláudio Nucci e Paulinho Tapajós. Em 1979, Sapato Velho foi gravada por Paulinho Tapajós em seu LP A história se repete e, em 1981, tornou-se um sucesso na versão do grupo Roupa Nova. Destacando apenas alguns aspectos desta enredada canção (Ex.7), pode-se notar que, o primeiro verso, "Você lembra, lembra, daquele tempo...", ambienta-se em uma prolongação harmônica do I grau do tom principal: Lá Maior. Mais adiante (c.21), o verso "Água da fonte cansei de beber" repousa em F\#m, o VIm grau, relativa menor do tom principal e, a partir daí, algumas áreas tonais mais remotas vão se fazer ouvir.

Como que revisitando a rota de Sechter (Ex.6), o início do verso "prá não envelhecer" (c.25-26) faz surgir a região de F\#:, submediante de Lá Maior, para rapidamente enfocar (c.27-30) a área tonal de Eb:, a submediante de F\#: situada à distância de trítono do tom principal. 0 verso "como quisesse roubar da manhã" (c.31-34), mantém o diatonismo de Eb:, mas esconde o I grau desta longínqua 
vizinhança (bV). 0 verso "um lindo por de sol" (c.35) se inicia na região de C:, a submediante de Eb: e blll grau da tonalidade de Lá Menor que, por empréstimo modal, se faz ouvir no tom de Lá Maior que, enfim, ressurge justamente quando se canta, novamente, o emblemático nome do astro "sol". Na linha melódica destaca-se o vínculo unificador recomendado por Hauptmann: a nota Dó\#, terça do acorde $A$, é reinterpretada como quinta do acorde F\# (c.26). A nota Lá\# que foi terça de F\# é reinterpretada como Sib, a quinta do acorde Eb (c.27). A nota Sol que foi terça de Eb é reinterpretada como a quinta do acorde $C$ (c.36). E a nota $\mathrm{Mi}$, terça de $\mathrm{C}$, ressurge como a quinta do acorde $\mathrm{A}$ (c.37).

Em suma, nos afastamos do diatonismo principal, poeticamente associado ao emblema "água da fonte", e para ele voltamos dando uma completa volta "sharpness" em um ciclo de submediantes $A: \rightarrow F \#: \rightarrow E b: \rightarrow C: \rightarrow A:$ Então, "a história se repete", o ciclo monotonal se repete. Mas, neste saudoso e lírico Sapato Velho, está engenhosamente distribuído em segmentos desiguais. Esta assimetria fraseológica suaviza a rigidez geométrica do círculo e, ao mesmo tempo, ajuda a escamotear outras simetrias harmônicas. Como aqui, os lugares de chegada I, VI, bV e bllI não são estereotipadamente precedidos pelas respectivas cadências "ii $\rightarrow V \rightarrow \mid$ ", as soluções de trânsito entre as quatro regiões do ciclo chamam atenção. Em pontos chaves da forma, diferentes acordes assumem função de um IV grau momentâneo que, estratégicamente, desempenha o papel de acorde pivô capaz de entremear as longínquas tonicizações. A saber: o acorde D (c.21) é IV grau de Lá Maior e bVI da vindoura área tonal de Fá\# Maior. 0 acorde B (c.25) é IV grau de Fá\# Maior e bVI da vindoura área tonal de Mib Maior. 0 acorde $A b$ (c.31) é IV grau de Mib Maior e bVI da vindoura área tonal de Dó Maior. 0 acorde $F$ (c.35) é IV grau de Dó Maior e bVI da vindoura volta ao tom principal, Lá Maior. Outro recurso
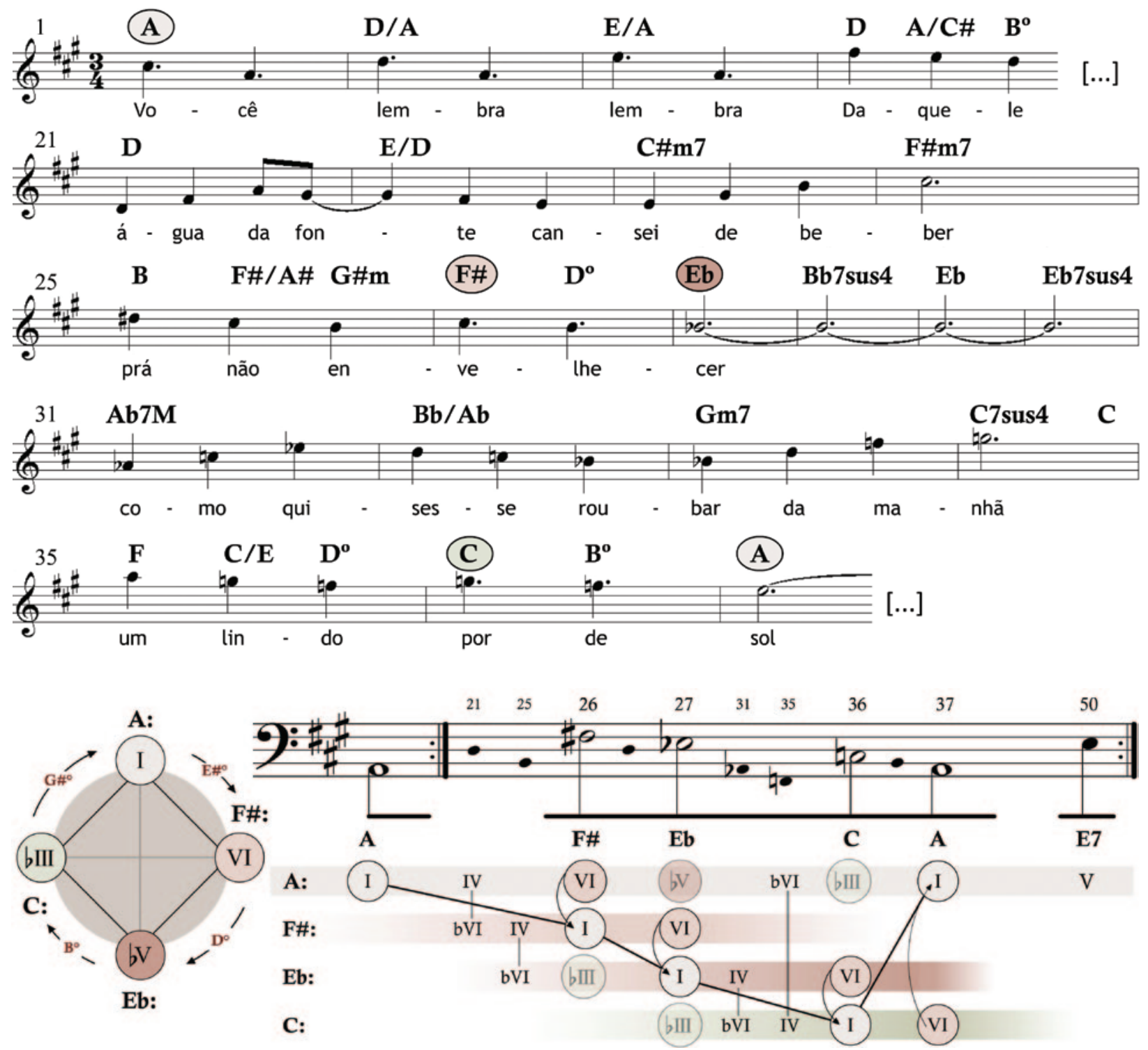

Ex.7 - 0 ciclo de terças menores em Sapato Velho de Mú Carvalho, Cláudio Nucci e Paulinho Tapajós, 1981 
de preparação que se observa é aquele da "modulação enarmônica baseada no acorde diminuto" (ALDWELL e SCHACHER, 1989, p.560-561). Ou seja: como os principais centros tonais da canção estão distanciados por terças menores, o mesmo acorde diminuto surge e ressurge para confirmá-los. Por reinterpretação enarmônica, G\#ºu uma de suas inversões, assume quatro diferentes papéis de preparação: $\mathrm{E \#} \rightarrow \mathrm{F \#}$; $\mathrm{D}^{\circ} \rightarrow \mathrm{Eb} ; \mathrm{B}^{\circ} \rightarrow \mathrm{C}, \mathrm{G} \#^{\circ} \rightarrow \mathrm{A}$.

\section{6 - Ciclos de terças maiores: o caso de Dom de lludir}

Neste cenário da indústria de entretenimento, as expansivas e românticas harmonias do "complexo AbC-E" contribuem para o efetivo sucesso da canção Dom de iludir de autoria do cantor e compositor baiano Caetano Emanuel Vianna Telles Velloso (1942-). Dentre as primeiras difusões de Dom de iludir, destaca-se a versão em Si Maior gravada por Gal Costa em seu LP Minha Voz de 1982. E foi na voz desta cantora que a canção tomou parte da trilha sonora de Louco Amor, telenovela de Gilberto Braga transmitida pela Rede Globo em 1983. Em 1986, Dom de iludir aparece gravada em Dó Maior pelo próprio Caetano Veloso, violão e voz, em seu álbum Totalmente demais ao vivo.

Conforme alguns dos aspectos abordados por GUEST (2006, p.110), no primeiro verso (c.1-4 no Ex.8), "Não me venha falar na malícia de toda mulher", a harmonia transita de I para bVI fazendo com que a palavra "mulher" (c.3) seja sublinhada pela "troca de cor" (LA MOTTE, 1993, p.157) da nota Sol (i.e., a quinta do acorde C7M é reinterpretada como sétima maior de Ab7M). 0 segundo verso (c.5-8), "Cada um sabe a dor e a delícia de ser 0 que é", conserva a metrificação poética do primeiro, mas a métrica harmônica não rima com a anterior $e_{\text {, sem }}$ repousar em qualquer lugar de chegada, confronta 0 afirmativo "é" do poema com uma preparação para E7M que, neste percurso, ainda é um vir a ser.

Como ocorre no Hino ao Sol e em Setembro, o principal meio de tonicização aqui é também a fórmula cadencial "ii $\rightarrow V \rightarrow \mid$ ". Mas neste segundo verso, lembrando uma solução empregada por Schubert (cf. FREITAS, 2010, p.243-247), a subdominante menor se destaca como um proveitoso acorde pivô. Note-se: Ab7M alcança seu IVm (Dbm) justo na sílaba forte da palavra "delícia" (c.6). E, por equivalência enarmônica, este Dbm passa a atuar como C\#m, o VIm da região de Mi Maior que aos poucos se instaura. Em Mi Maior, o terceiro verso (c.9-12) recupera o "modelo" $\mid \rightarrow b \mathrm{bl}$ do primeiro verso, partindo agora da mediante (E7M, o indireto, porém próximo, III grau do tom principal), que ambienta a metafórica reivindicação do poeta: "Não me olhe como se a polícia andasse atrás de mim". E agora (c.11), é a troca de cor da nota Si (a quinta de E7M reinterpretada como sétima maior de $\mathrm{C} 7 \mathrm{M})$ que assinala o a si mesmo enunciado pelo pronome

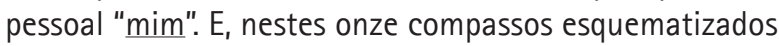
no Ex.8, o ciclo $C: \rightarrow A b: \rightarrow E: \rightarrow C$ : se fecha.
Tal destaque ao "complexo Ab-C-E" em Dom de iludiré uma oportunidade para a observação de mais alguns pontos de contato entre estas escolhas recentes e determinadas memórias, artísticas e especulativas, que acompanham os ciclos de terceira há mais tempo. Com as normalizações de Sechter e Hauptmann, lembradas aqui como marcos da linhagem teórica austro-germânica em meados do século XIX (cf. BERNSTEIN, 2006; WASON, 1988), importa referenciar algo das contribuições que, na viragem para o século XX, Rimsky-Korsakov e Hugo Riemann deram ao tema dos ciclos de terceira, pois é possível notar congruências entre tais contribuições e determinadas ocorrências em músicas populares do século XX.

Um registro dos entendimentos do compositor, teórico e professor russo Nikolai Andreyevich Rimsky-Korsakov (1844-1908) encontra-se no "\$294 Falsas Progressões ao longo do círculo de terças maiores" e "\$298 Falsas Progressões ao longo do círculo de terças menores" de seu Uchebnik garmonii, o Tratado de harmonia produzido entre 1884-85 que foi revisto e ampliado em 1886 como Prakticheskiy uchebnik garmonii, o Tratado prático de harmonia (cf. SCHUSTER-CRAIG, 1999; TARUSKIN, 1985, p.136-139; 1996, p.302-306). Como se sabe, o Tratado prático de Rimsky-Korsakov foi, e ainda é, conhecido nas escolas de música do Brasil e da América Latina e, na versão em língua espanhola, as demonstrações dos ciclos de terceira se encontram no $\$ 90$ (cf. RIMSKY-KORSAKOV, 1946, p.128). Na cena internacional da música de concerto, tais harmonias estão associadas aos avançados construtos harmônicos do nacionalismo russo (cf. TARUSKIN, 1996, p.261-261; SCHUSTER-CRAIG,1999). E, conforme TARUSKIN (1996, p.302), o influente Igor Fyodorovich Stravinsky (1882-1971) possivelmente conheceu tais harmonias simétricas através desta vertente, uma vez que, em seus anos de aprendiz, Stravinsky estudou o Tratado prático sob a supervisão de Vasily Pavlovich Kalafati (1869-1942) e de Fyodor Stepanovich Akimenko (18761945), dois alunos do próprio Rimsky-Korsakov em São Petersburgo. Nos EUA, onde os ciclos de terceira são um tema de considerável destaque no repertório popular, essa vertente russa disseminou-se também através do trabalho de músicos e professores oriundos do leste europeu. Dentre estes músicos emigrantes, quando se trata da questão dos ciclos de terceira na música de jazz, destaca-se o nome de Nicolas Leonidovich Slonimsky (1894-1995), compositor, regente e professor nascido em São Petersburgo que imigrou para os EUA em 1923 levando consigo uma formação musical desenvolvida numa época e lugar aonde Rimsky-Korsakov era uma figura central. Em 1947, Slonimsky publicou o Thesaurus of scales and melodic patterns, uma pesquisa inserida no contexto da nova música erudita que se tornou uma espécie de livro obrigatório no meio jazzístico em meados de 1950 (cf. PORTER, 1999, p.149).

Atualmente, diversos autores (cf. BAIR, 2003; DEMSEY, 1996; JAFFE, 1996, p.163) demonstraram cabalmente que, certos padrões de Slonimsky foram citados, ou 

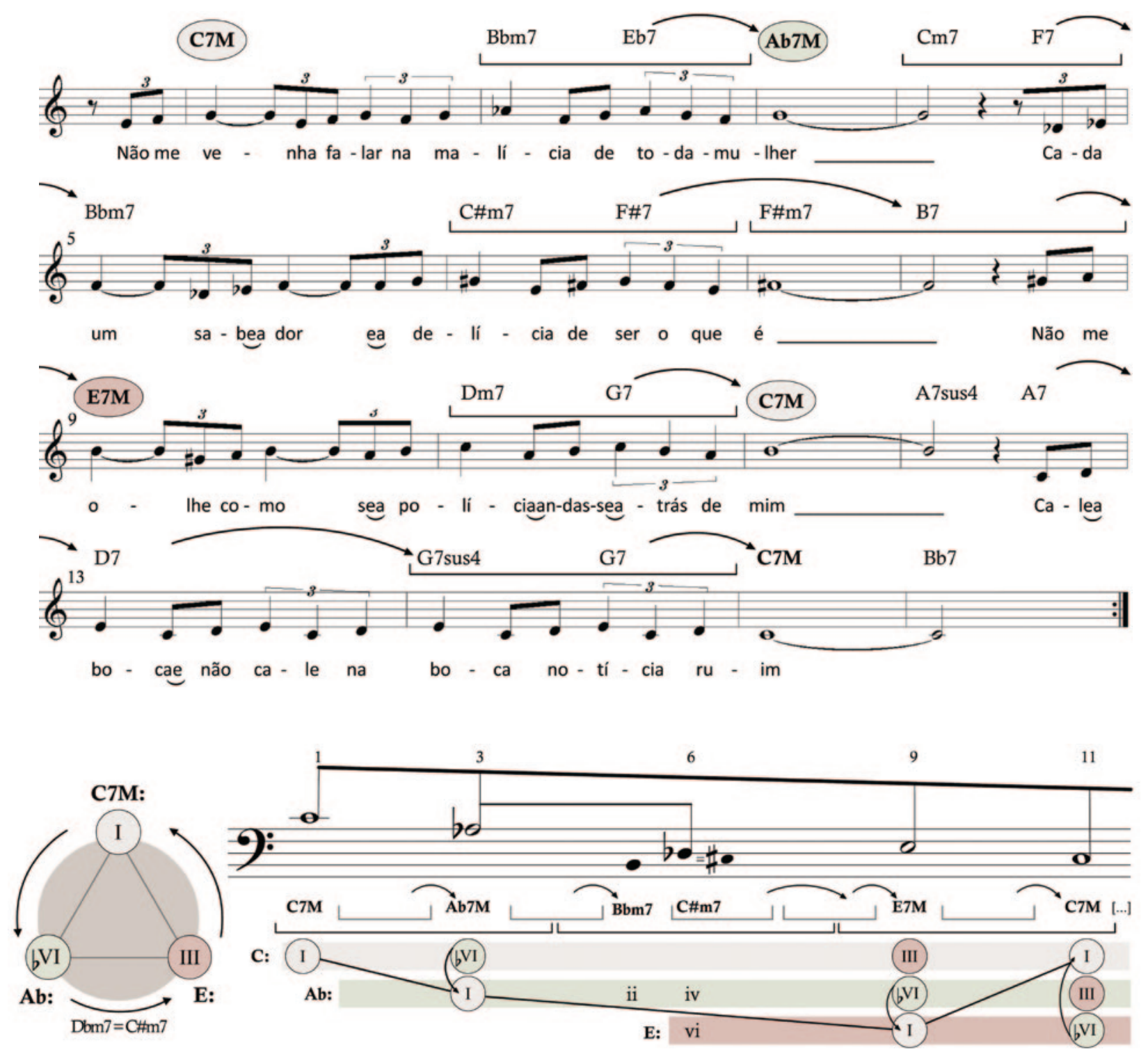

Ex.8 - 0 ciclo de terças maiores em destaque na canção Dom de lludir de Caetano Veloso, 1986

recriados, naquele que é considerado o locus classicus dos ciclos de terças maiores no campo jazzístico e popular: o tema de Giant Steps, composição de John Coltrane lançada em 1959. 0 contorno melódico dos c.8-13 de Giant Steps (tema que possui 16 compassos) corresponde ao padrão "n 286" do Thesaurus, e a conexão melódico harmônica entre a "ditone progressions" de Slonimsky (ditones são intervalos de dois tons, i.e., terça maior) e a "progressão Giant Steps" é flagrante no "Pattern n ${ }^{\circ}$ 646" (cf. SLONIMSKY, 1975, p.vi e 40). Com o prestígio de Giant Steps, o ciclo de terça maior tornou-se conhecido na jazz theory por termos como: Coltrane matrix, Coltrane cycle, progressão giant etc. E como importa notar aqui, o plano tonal de Dom de iludir (Ex.8) revisita, a sua própria maneira, os mesmos lugares de chegada do complexo $\mathrm{Eb}: \rightarrow \mathrm{B}: \rightarrow \mathrm{G}$ : que notabilizou Giant Steps (Ex.9). ${ }^{6}$

Assinalado algo dessa vertente russa e algumas pistas de suas imperscrutáveis repercussões, deve-se também notar que, entrementes, provavelmente o mais popular dentre os registros que atestam a aceitação lexicológica do ciclo de terças maiores é a famosa progressão $C \rightarrow A b \rightarrow C \rightarrow E \rightarrow C$ (Ex.10) que passou a figurar no verbete "Tonalidade" do Musik-Lexikon que o musicólogo alemão Karl Wilhelm Julius Hugo Riemann (1849-1919) fez publicar a partir de 1882: "Tais sons" (acordes ou áreas tonais), argumenta RIEMANN (1908, p.796), "embora ninguém possa negar que o ouvido os receba como pertencentes ao mesmo tom, não eram considerados possíveis para o antigo sistema da harmonia".

Com Riemann, teórico que é lembrado, e por vezes esquecido, como o proponente da vertente, grosso modo, conhecida como "harmonia funcional", voltamos ao território da culta teoria austro-germânica. Mas, no caso, é preciso sublinhar que esta figura (Ex.10) não faz parte de um Harmonielehre de árdua leitura técnica e dedicado ao músico especialista. Hoje bastante 
debatida profissionalmente (cf. BERNSTEIN, 1993, p.391; BRIBITZER-STULL, 2006a, p.178-179; CINNAMON, 1986, p.4; COHN, 1996, p.10; DAHLHAUS, 1990, p.10; KOPP, 2002, p.80; PROCTOR, 1978, p.158; REHDING, 2008, p.48-49, 196; SOMER,1995, p.215-216; WASON, 1995, p.105), esta sintética figura foi estampada em um dicionário publicado em várias línguas e voltado para a formação geral do aficionado comum. Tal divulgação ainda dependeu da mediação de músicos letrados, mas esteve consideravelmente mais próxima daqueles que atuaram na desenvolução da canção popular urbana e massiva no correr do século XX.

A figura de Riemann pode ser vista como emblema de uma classificação de uso geral que apreende o chamado "complexo Ab-C-E" como uma totalidade razoavelmente coerente e unificada. Nessa totalidade, os componentes interagem em diversificadas relações de subordinação e interdependência e tais interações dependem de uma intelecção percebida como complexa. Essa imagem geral de coesão sofisticada contribui para o prestígio peculiar desses ciclos. Um prestígio relacional, não autônomo, sujeito a uma dinâmica de estimações comparadas: complexidade é valor que depende de algum contraste com um não complexo, o inusual depende de experiência com o usual, o intenso ultrapassa as medidas ordinárias, o surpreendente observa o previsível etc. Assim, mesmo quando se lê que os enlaces de terças maiores são "uma técnica cromática muito utilizada pelos compositores do século XIX" (SALZER e SHACHTER, 1999, p.182), devemos estar atentos: 0 alto prestígio dessas harmonias não corresponde necessariamente a um alto índice de incidência. Tais ciclos foram (e são) usados como sinais de raridade. No âmbito da norma tonal, são distinções de inovação, ousadia e extraordinariedade. São traços da arte de gênio. Não vieram para se colocar em pé de igualdade ou para tomar o lugar das "correspondências de quinta":

\footnotetext{
Estas classificações de uso geral nos inclinam a crer que no caso das relações de terceira se trataria também de um material de construção harmônica, por assim dizer, anônimo e disponivel em geral. Porém, [...] as relações de terceira continuam sendo também no romantismo enlaces muito mais infrequentes do que os enlaces de dominantes; quer dizer, são algo especial! [Em seu uso] predominam os traços individuais dos distintos compositores e de diferentes situações compositivas. Digamos que uma série Dominante-Tônica é algo que "se emprega". Enquanto que, uma série de acordes em correspondência de terceira é algo que "se inventa" (LA MOTTE, 1993, p.155-156).
}

Em música popular, quando se trata do ciclo de terças maiores, talvez o caso mais citado seja mesmo o Giant Steps. Mas, tais enlaces se fizeram ouvir em outros repertórios. Como a próxima canção é oriunda da cena do teatro musical no Brasil, é oportuno rememorar certas canções dos musicais norte-americanos que, com a difusão massiva, podem ter dialogado com a trajetória da canção popular produzida em nosso país. Dentre os hits, diferentes recriações do ciclo de terças maiores se fazem ouvir nos planos tonais de: Bess, You is My Woman de George e Ira Gershwin de 1935, Have you met Miss Jones? de Richard Rodgers e Lorenz Hart de 1937, All The Things You Are de Jerome Kern e Oscar Hammerstein II de 1939, The Midnight Sun de Lionel Hampton e Sonny

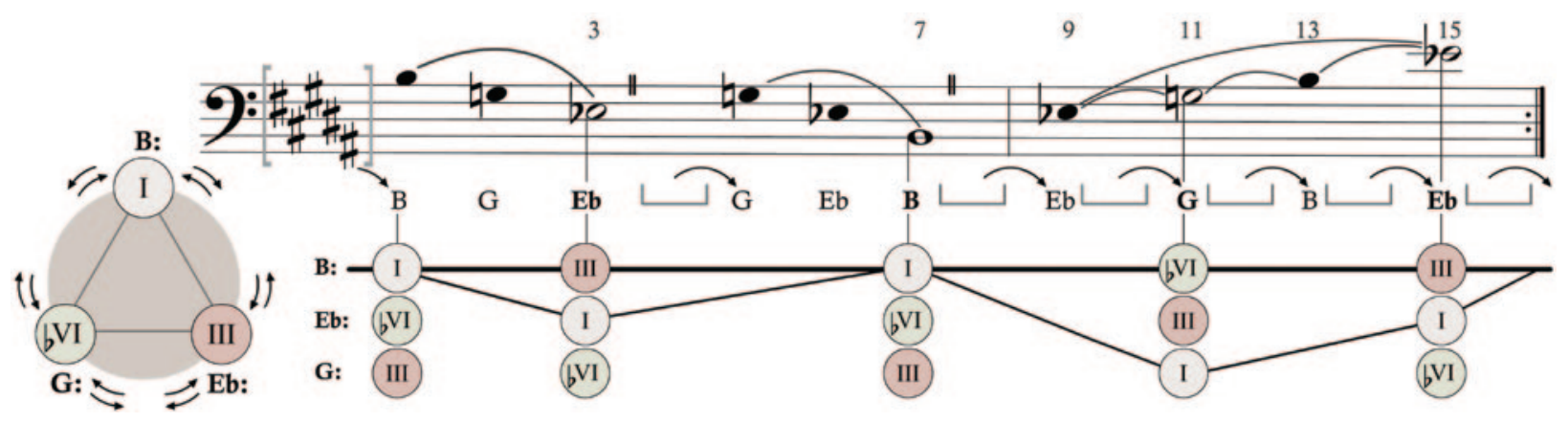

Ex.9 - 0 ciclo de terças maiores em destaque no plano tonal de Giant Steps de John Coltrane, 1959
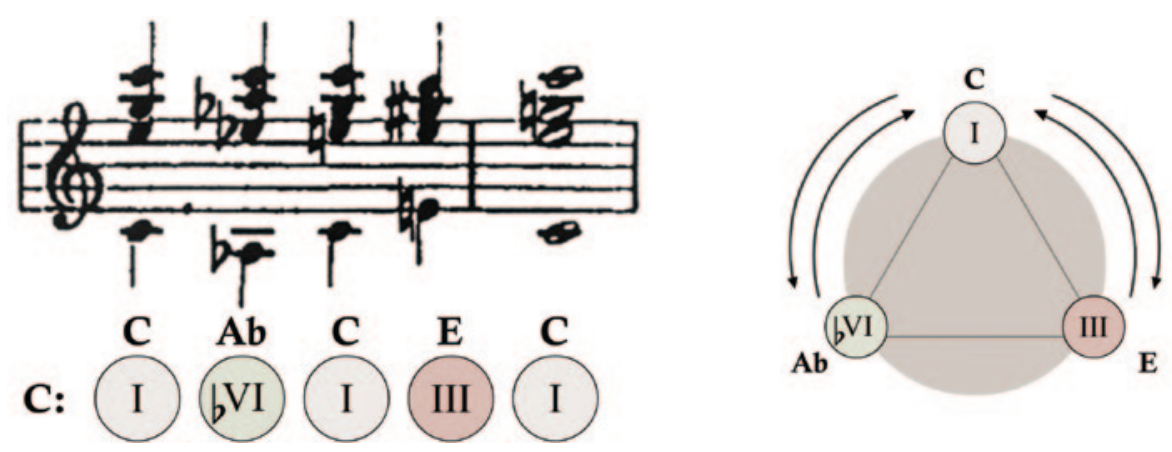

Ex.10 - 0 ciclo de terças maiores como emblema da concepção contemporânea de tonalidade, conforme Riemann 
Burke de 1947, Baubles, Bangles \& Beads creditada a Robert Wright e George Forrest de 1953, e If Ever I Would Leave You de Alan Jay Lerner e Frederick Loewe de 1960 (cf. FREITAS, 2010, p.726-728).

\section{7 - 0 caso do ciclo de terças maiores em Choro Bandido}

A canção Choro Bandido é um dos frutos da parceria entre os cantores e compositores Eduardo de Góes Lobo (1943-) e Francisco Buarque de Hollanda (1944-). Seu surgimento, como se sabe, se deu em meio ao contexto da criação e produção do musical 0 Corsário do Rei, escrito e dirigido entre aproximadamente 1982-85 pelo dramaturgo e ensaísta brasileiro Augusto Boal (19312009), no ensejo do seu retorno aos palcos brasileiros após 14 anos no exílio. A primeira gravação comercial de Choro Bandido, com a participação de Tom Jobim, encontrase no álbum que reúne as canções deste musical, todas creditadas a Edu Lobo e Chico Buarque, o LP O Corsário do Rei lançado pela gravadora Som Livre em 1985.

Por conta de tantos fatores imbricados, não é tarefa simples rastrear aquilo que foi posto junto no trabalho de composição desta canção. Fatores diversos, que não serão comentados aqui, que passam pela conjuntura sociopolítica cultural carioca, pelo momento do mercado musical e pelas reconhecidas capacidades criativas destes protagonistas atuando nesse cenário. Passam também pelo denso argumento teatral, pelas imagens da mitologia greco-latina que visitam os versos da canção, pelo detalhamento dos sinuosos intervalos da sua melodia e arranjo, e também pela consideração do que já foi dito a respeito deste Choro Bandido que seguiu exitoso caminho após a encenação teatral. Contudo, contando com certo esforço de redução, pode ser contributivo notar que, também aqui, as correspondências de quintas atuam como um marco da ordem normal, um enlace comum que, como termo de comparação, ressalta a invulgar correspondência de terças maiores que subjaz no plano tonal da canção.

Após a introdução, conforme a versão em pauta publicada por Edu Lobo (1994, p.115-119) que serve de referência para o esquema traçado no Ex.11, os versos iniciais do
Choro Bandido ("Mesmo que os cantores sejam falsos como eu / Serão bonitas, não importa / São bonitas as canções / Mesmo miseráveis os poetas / Os seus versos serão bons") ambientam-se em uma prolongação do । grau de Dó-Maior, o tom principal. Os enlaces nestas duas quadraturas (c.1-4 e c.5-8) são basicamente passos de quinta. Digamos: repetições ornamentadas da fórmula cadencial "ii $\rightarrow$ V". Dentre as tensões e distensões com as quais a melodia convive, surge a quinta aumentada (c.7) que, estrategicamente posicionada, tensiona o I grau bem ao momento em que se alcança o primeiro ponto culminante: a nota Si em C7M ${ }^{(\# 5)}$ quando, na afirmativa "Os seus versos serão bons", se canta justamente o adjetivo "bons". Tal acorde de quinta aumentada demarca um ponto de chegada, mas é também um bom ponto de partida.

Ao longo do século $X X$, o acorde de quinta aumentada se destacou em canções que, em momentos diferentes e por razões diversas, ficaram associadas a exaltação da brasilidade. Canções emblemáticas como Carinhoso de Pixinguinha, Aquarela do Brasil de Ary Barroso, Pedro Brasil de Djavan, Coração de Estudante de Wagner Tiso e Milton Nascimento, $E$ de Gonzaguinha etc. E tal estima nacional pelo acorde de quinta aumentada dá pistas da admiração que nutrimos por outra idealização nacionalista. A triade aumentada gozou de alto prestígio na chamada Neudeutsche Schule, e nessa Nova escola alemã, o nome do compositor húngaro Franz Liszt (1811-1886) se destaca como um dos grandes cultores do acorde de quinta aumentada (cf. LA MOTTE, 1993, p.239-250; MENEZES, 2002, p.84-92; 2006, p.75-89; TARUSKIN, 1996, p.263-272). Com isso, também na harmonologia austro-germânica, a tríade aumentada é tratada como um tema de alto apreço (cf. SCHOENBERG, 2001, p.347-352, 538-542). A este respeito seria possivel voltar mais uma vez a 1853, ano em que o compositor e teórico alemão Carl Friedrich Weitzmann (1808-1880) publicou a monografia Der übermässige Dreiklang (A tríade aumentada) tecendo 32 páginas de considerações sobre as propriedades deste acorde (cf. COHN, 2000; TODD, 1988; SASLAW, 1992, p.369-373). Weitzmann demonstra que a reinterpretação enarmônica de uma tríade aumentada permite empregá-la como um tipo especial de acorde pivô capaz de intermediar vizinhanças

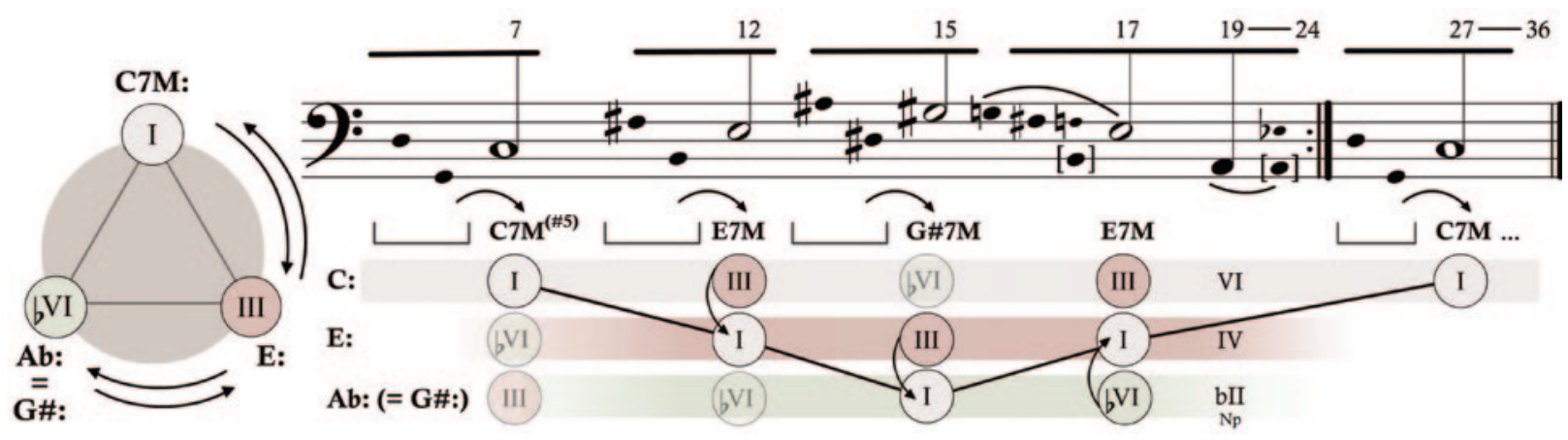

Ex.11 - 0 ciclo de terças maiores em destaque no Choro Bandido de Edu Lobo e Chico Buarque, 1985 
sem afinidades diatônicas evidentes. Dentre outras possibilidades, destaca-se a engenhosa intermediação das distantes vizinhanças do ciclo de terças maiores, posto que, enarmonicamente, as tríades $A b^{(\# 5)}, C^{(\# 5)}$ e $E^{(\# 5)}$ são anagramas umas das outras, rearranjos das mesmas três notas. $\mathrm{E}$, é a partir deste $\mathrm{C} 7 \mathrm{M}^{(\# 5)}$, uma espécie de cartão de visita para as vindouras áreas tonais de III (Mi Maior) e bVI (Láb Maior), que o Choro Bandido segue para enlaces harmônicos mais expandidos.

A quadratura seguinte (c.9-12) perpassa um inequívoco "ii $\rightarrow \bigvee \rightarrow \mid$ " em Mi Maior, a região de Mediante que, com quatro acidentes ocorrentes, contrasta os versos "Mesmo porque as notas eram surdas / Quando um deus sonso e ladrão". 0 próximo "ii $\rightarrow \mathrm{V} \rightarrow \mid$ " já está na área tonal de Láb Maior (enarmonizada como Sol\# Maior) e traz os versos "Fez das tripas a primeira lira / Que animou todos os sons" (c.13-16). Os próximos oito compassos (c.1724) retomam a região de Mi Maior: "E daí nasceram as baladas / E os arroubos de bandidos como eu / Cantando assim: / Você nasceu para mim / Você nasceu para mim". Até que o ritornelo (c.24) anuncie o "ii $\rightarrow V \rightarrow \mid$ " no tom principal, que reinicia o ciclo com os versos da segunda estrofe.

Então, mesmo com uma descrição parcial e insuficiente, já é possível notar que se trata de uma recriação do "complexo Ab-C-E". Aqui numa versão parcimoniosa e camuflada se comparada ao famoso e aparentado plano tonal de Giant Steps. Uma versão que distribui as três principais áreas tonais em uma simetria alongada: 8 compassos em C:, 4 compassos em E:, 4 compassos em Ab:, 8 compassos em E: e, por fim, 8 compassos em C: arrematados por uma coda plagal de 4 compassos. Com isso, a artesanalidade complexa do Choro Bandido também se mostra atenta ao argumento de que, "em música, uma das descobertas do romantismo foi a de como ocultar a convenção sem renunciar a ela. Os padrões estabelecidos podiam ser usados, porém disfarçados de alguma maneira" (MEYER, 2000 p.321). Atenta a um valor artístico que é reclamado pelos diversos cultores dos planos tonais difíceis. Valor que, em 1827, foi filosoficamente sintetizado pelo influente Johann Wolfgang von Goethe (1749-1832) nos seguintes termos: "quanto mais incomensurável e menos racionalmente compreensivel resulte a produção poética, tanto melhor" (Goethe, citado por KUNZE, 1990, p.597). E que, em 1959, transparece no texto de contracapa do álbum Giant Steps ao momento em que Coltrane escreve: "eu sento e toco progressões e sequências de acordes e, no fim, tiro uma música, ou mais de uma, de cada probleminha musical".7

\section{8 - 0 caso do ciclo de terças maiores no refrão de Amazon River}

Nos dois últimos casos (Ex.8 e 11), os probleminhas do ciclo de terças maiores estão poeticamente associados aos assuntos da natureza que está dentro de nós. Digamos: a canção de Caetano Veloso apresenta uma espécie de reflexão moral ("A verdade é o seu dom de iludir / Como pode querer que a mulher vá viver sem mentir") que, de outra maneira, também perpassa - Choro Bandido na alusão ao "deus sonso e ladrão", Hermes, o deus do engano. Agora, no caso da canção Amazon River, como ocorre com o Hino ao Sol, os trajetos simétricos voltam a ambientar o tema da exaltação da natureza que está fora de nós.

0 refrão da canção Amazon River, com música do cantor e compositor Dorival Tostes Caymmi (1943-) e letra de Paulo César Pinheiro (1949-), é um trecho musical de aproximadamente 48 compassos que possui uma gênese gradual. Podemos ouvi-lo como segmento final de Obsession, composição de Gilson Peranzetta, Tracy Mann e Dori Caymmi, lançada no álbum Dori Caymmi de 1988. Outra versão do trecho reaparece, ainda sem letra, como refrão da canção Amazon River que abre o álbum Brasilian Serenata lançado por Dori Caymmi em 1991. E a versão com a letra de Paulo César Pinheiro e a voz de Dori Caymmi pode ser apreciada no álbum Mundo de dentro lançado por Dori Caymmi no Brasil em 2009.

Os comentários que acompanham os Ex.12 e 13 baseiamse na versão em pauta disponível no site oficial do compositor (CAYMMI e PINHEIRO, 1991). Nesta versão, comentada com mais detalhes em FREITAS (2010, p.302307), o prestigioso ciclo de terças maiores transita pelos mesmos tons que ouvimos na emblemática Giant Steps.

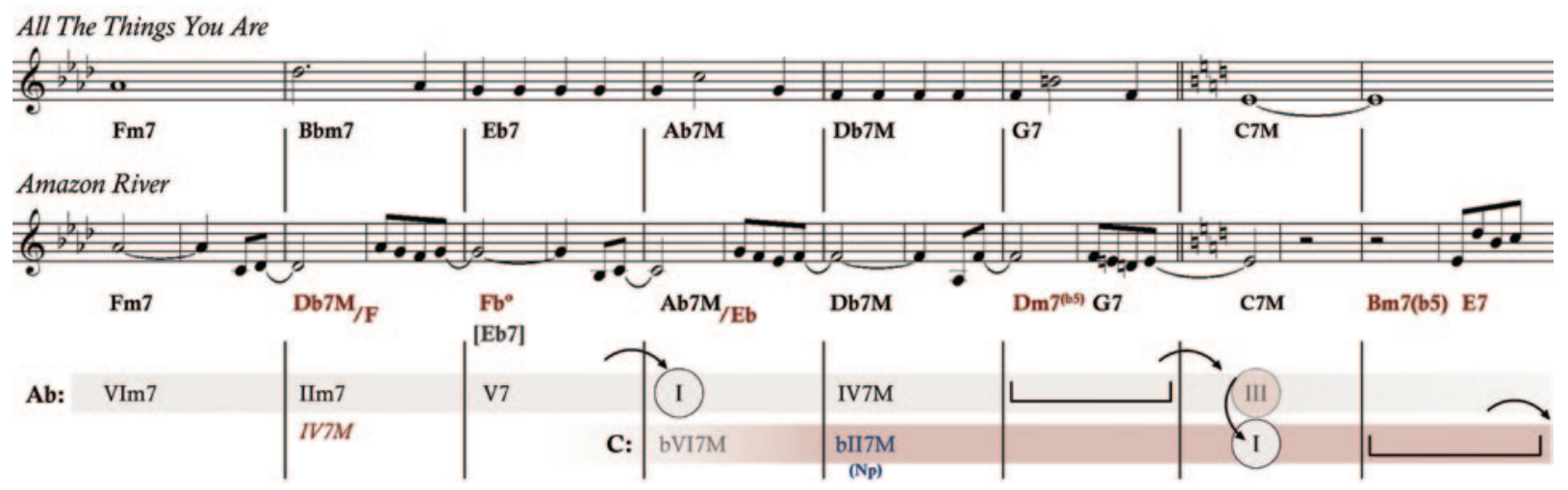

Ex.12 - 0 verso do refrão de Amazon River (transposto para Láb Maior) visto como paráfrase da primeira estância de All The Things You Are 


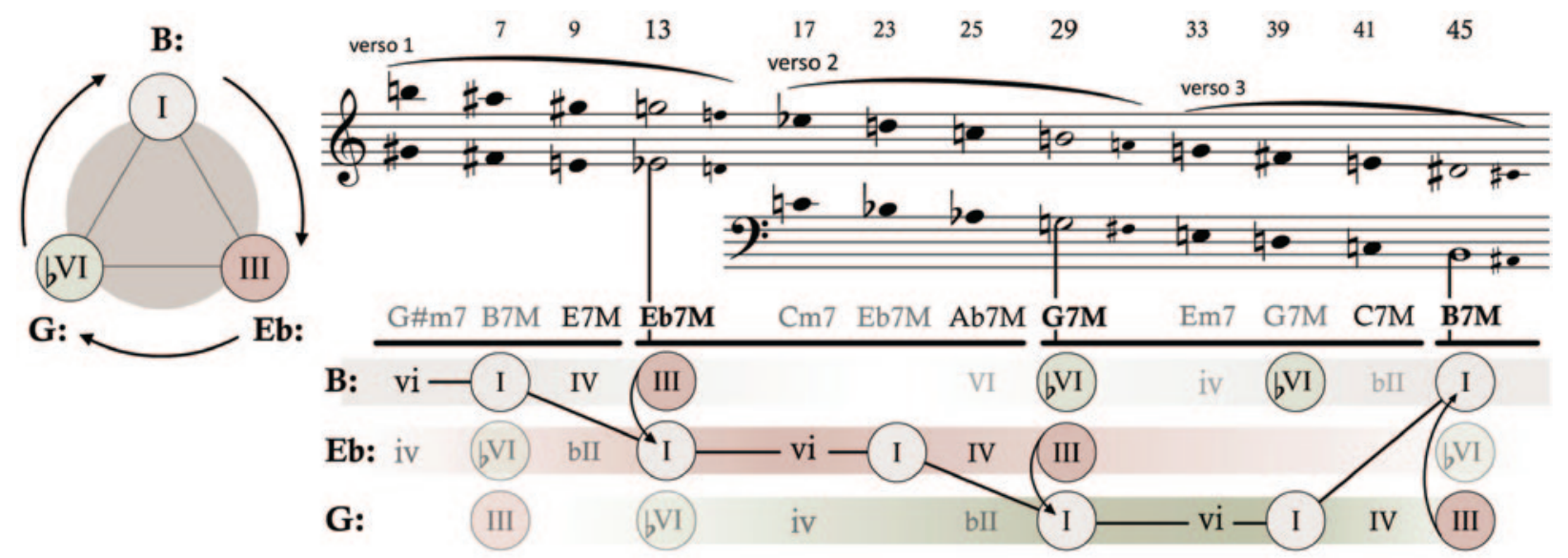

Ex.13 - 0 ciclo de terças maiores no último refrão de Amazon River de Dori Caymmi e Paulo César Pinheiro

Mas no refrão de Amazon River, a aparição dos respectivos primeiros graus de cada região $(B 7 M \rightarrow E b 7 M \rightarrow G 7 M)$ está escondida por meio de recursos engenhosos. Cada verso (cada segmento de 16 compassos) começa com o VIm7 de sua respectiva área tonal. Com isso, a triangulação de Amazon River é por vezes citada como um caso ainda mais raro: $\mathrm{GHm} \rightarrow \mathrm{Cm} \rightarrow \mathrm{Em}$. Ou seja, um suposto ciclo de terças maiores entre acordes menores (cf. SCHOENBERG, 2001, p.348). Outro fator de disfarce é o fato de que, o primeiro repouso tônico de cada verso (c.7-8, 23-24 e 39-40) se dá em posição métrica não acentuada. Isto desvia a atenção do I grau e favorece as mudanças de região, como podemos ouvir nos primeiros 8 compassos da supracitada canção All The Things You Are que, como mostra o Ex.12, podem ser vistos como a referência parafraseada no verso de 16 compassos que se repete três vezes neste refrão de Amazon River.

Somando-se aos recursos de disfarce, nestes momentos de repouso imperfeito, em cada verso, o correspondente I grau aparece em segunda inversão. Uma sonoridade menos explícita e, por vezes, coloquialmente apontada como uma preferência da "harmonia brasileira". Neste caso (Ex.13), a segunda inversão (B7M/F\# no c.7, EbM/ Bb no c.23 e G7M/D no c.39) é irrecusável em virtude da linha descendente do baixo que, com as notas estruturais da melodia, mantêm um movimento de décimas paralelas ao longo dos 48 compassos do refrão. No momento em que se concluem cada uma das três periodicidades da melodia (c.13, 29 e 45), o segundo repouso tônico marca o início de uma nova e distante área tonal, a região de mediante. Ou seja: por meio de uma espécie de desencaixe, ou elisão, a melodia pára e descansa, enquanto a harmonia já inicia uma nova jornada de 16 compassos. Outro fator que ajuda a esconder a identidade dos "primeiros graus" que sustentam o ciclo $\mathrm{B} 7 \mathrm{M} \rightarrow \mathrm{Eb} 7 \mathrm{M} \rightarrow \mathrm{G} 7 \mathrm{M}$ é a combinação entre enarmonias e os múltiplos significados de determinados acordes. Um destes múltiplos significados permite o reaproveitamento sensivelmente estirado do VIm grau: no primeiro verso (c.1-16), G\#m é VIm do tom de saída, Si Maior, e IVm da vindoura área tonal de Mib
Maior. No segundo verso (c.17-32), Cm é VIm de Mib Maior e IVm de Sol Maior. E no terceiro verso (c.33-48), Em é VIm de Sol Maior e IVm de Si Maior.

Neste retrato das águas de um rio, outra ambiguidade eficiente decorre de um reaproveitamento da versátil capacidade pivô do "acorde de sexta napolitana", lembrando que: "Se a tonalidade deve flutuar, terá, em algum ponto, de estar firme. Porém, não tão firme que não possa movimentar-se com soltura. Para isto são adequadas duas tonalidades que possuam alguns acordes em comum; por exemplo, a sexta napolitana" (SCHOENBERG, 2001, p.528). Assim, com a reincidente reinterpretação do acorde perfeito maior como um acorde de sexta napolitana, a solução de firmeza e soltura que enlaça as regiões do refrão de Amazon River nos conduz por uma espécie de círculo vicioso: no c.9, o acorde E7M (IV de Si Maior) é reinterpretado como bll (Np) de Mib Maior. No c.25, o acorde AbM (IV de Mib Maior) é reinterpretado como bll (Np) de Sol Maior. E no c.41, o acorde C7M (IV de Sol Maior) é reinterpretado como o bll (Np) de Si Maior, a região que retoma o primeiro verso. Contando com tais disfarces, os três versos "modulantes" (B: $\rightarrow \mathrm{Eb}:$ Eb: $\rightarrow \mathrm{G}:, \mathrm{G}: \rightarrow \mathrm{B}:)$ do refrão de Amazon River reelaboram de maneira bastante sofisticada aquela "lógica" que, em 1853, HAUPTMANN (1888, p.152-153) descreveu de maneira bastante simples: em sentido ascendente, os ciclos de terças maiores decorrem da reinterpretação da terça maior de um I grau de saída (Ré\# de Si Maior), como a fundamental de um novo tom de chegada (Mib Maior).

Por fim, note-se a reafirmação da emblemática associação entre as belezas naturais e as relações de mediante $(I \rightarrow|I|)$. 0 principal enlace harmônico (B: $\rightarrow E b: \rightarrow G:$ ) do refrão de Amazon River reitera, começando meio tom acima, aquele célebre trajeto $\mathrm{Bb}: \rightarrow \mathrm{D}$ : que Beethoven percorreu na Sinfonia Pastoral. E tal trajeto (c.151-163 do $1^{\circ}$ movimento da Sinfonia n.6, op. 68, em Fá-maior), é parte de uma solução composicional que atendeu a uma sugestão programática geral que é consideravelmente comparável ao caso aqui em apreço. 
Em seu rascunho [da Sinfonia Pastoral] de 1804, Beethoven pode ter antecipado a ideia de correlacionar a origem do riacho com a origem [...] do movimento inteiro. Aqui ele escreveu um tema [...] que representa o movimento do riacho [ou rio] com a anotação "Je größer der Bach, je tiefer der Ton" (LOCKWOOD, 2004, p.266).

A famosa anotação de Beethoven pode ser aproximadamente traduzida como: "quanto maior (mais profundo, mais largo) o riacho, mais profundo o tom (caráter, traços comportamentais e afetivos)". E tal anotação parece adequada ao tom evocado aqui pelos cancionistas Dori Caymmi e Paulo César Pinheiro: "Nas águas do Rio Amazonas / 0 meu coração se banhou". No refrão, os versos decantam fotogramas da nossa pátria numa espécie de revival daquele gênero de samba exaltação, tipo exportação, que marcou época durante 0 Estado Novo (cf. FURTADO FILHO, 2010; SOARES, 2002). E então, girando sempre em sentido "sharpness" $|\rightarrow||| \rightarrow b V I$, os lugares do ciclo de terças maiores vão se mesclando aos versos: "Brasil! / No bananal, Brasil / No pantanal, Brasil / No rio-mar / Lá no sertão, Brasil / No litoral, Brasil / Meu coração, Brasil / Pôde escutar / Um sabiá, Brasil / Um pé de pau-brasil / que me ensinou, Brasil / o meu cantar". Para uma referência contrastiva, vale também recuperar que, em sentido "flatness" $\mid \rightarrow b V I \rightarrow I I I$, ou seja, em afeto adverso, esses mesmos lugares se enlaçam naquele célebre episódio conhecido como "acordes do sono", ou "harmonias do sono", o trecho que ouvimos a partir do c.638 no ato 3, cena 3, do drama musical Die Walküre (A Valquíria) concluído por Wagner em 1870 (cf. FREITAS, 2010, p.732733; HARRISON, 1994, p.318-319; KARG-ELERT, 2007, p.280; SALZER e SHACHTER, 1999, p.185-188).

\section{9 - Considerações finais}

Os fatores que contribuem para a fortuna rara e prestigiosa dos ciclos de terceira (menor ou maior) no âmbito da canção popular contemporânea são diversos e estão imbricados uns nos outros. Por um lado, são notórias as reminiscências dos valores românticos, valores que estão sendo minimamente lembrados aqui a partir do estudo de MEYER (2000). Neste âmbito romântico e popular, tais ciclos são, ou são percebidos como, soluções musicais objetivas, mensuráveis, que traduzem idealizações subjetivas de originalidade, inovação, inspiração e genialidade. São sinais de inconformismo, de depreciação das convenções e de valorização da expressão imediata. São traços de escolha, individualização, nacionalização, de estado de anseio e de devir contínuo. Tais ciclos estão associados aos valores de uma arte musical plena de mistério e inexplicabilidade, de profundidade e tortuosidade, de incompreensibilidade e ambiguidade, de espontaneidade, sentimento, raridade, diferença, grandiosidade e mudança. Uma harmonia complexa feita por e para iniciados, representativa da expansão tonal, das misturas cromáticas, dos disfarces inusitados e das tiradas surpreendentes.

A ideia de originalidade, que se impôs como o princípio estético dominante desde os finais do século XVIII, combinava a demanda de que, na música "autêntica", o compositor deveria expressar as emoções de seu ser interior com o postulado da novidade. Junto com as ideias melódicas, o que o século XIX mais valorizava como "inspirações" eram os acordes que fossem surpreendentes e ao mesmo tempo inteligiveis. Tais acordes eram tidos como expressivos - usando-se a palavra "expressão" com um sentido forte para referir-se à representação da experiência interior fora do comum através do emprego de meios inusuais - e se esperava que ocupassem seu posto na evolução histórica da música, uma evolução que se via como uma cadeia de invenções e descobertas (Dahlhaus, citado por MEYER, 2000, p.421).

Por outro lado, tais simetrias carregam consigo certos vestígios das doutrinas clássicas que também nos alcançam no senso comum. Este tipo de planejamento arquitetônico ressalta o valor intrínseco da "concinnitas" (a boa disposição, a elegância geométrica, a ordem matemática etc.), conservando memórias da antiga premissa de que os inversos aditivos possuem beleza e razão autônomas. Assim, o apreço pelos enlaces harmônicos equidistantes, reitera valores de fundo que perpassam a história artística e musical ocidental:

A doutrina do Belo como simetria foi apresentada pela primeira vez por Aristóteles. [...]. 0 Belo é constituido, segundo Aristóteles, pela ordem e pela simetria e por uma grandeza capaz de ser abraçada no seu conjunto por um só golpe de vista. [...] Simetria é comensurabilidade, proporção ou harmonia. Simétrica diz-se de uma relação que intercorre entre dois termos nos dois sentidos: p.ex. é simétrica a relação "irmão" (ABBAGNANO, 1982, p.101 e 868).

As palavras harmonia e simetria estavam [desde o período clássico grego] estreitamente relacionadas com a aplicação da teoria [de que a beleza se encontra naqueles objetos cujas partes mantêm uma perfeita relação geométrica proporcional entre si] aos âmbitos do ouvido e da visão. [Nos Dez livros sobre Arquitetura, c. 40 a.C] Vitrúvio desenvolve a ideia de que um edifício é belo quando todas as suas partes têm as proporções apropriadas de altura e largura, e de largura e longitude, e cumpram em geral, todas as exigências de simetria (TATARKIEWICZ, 2002, p.157).

Anos depois, em diversas passagens do influente verbete "0 Gosto" publicado na Encyclopédie em 1757, o filósofo francês Charles de Montesquieu (1689-1755) salienta correspondências entre os prazeres da ordem, da variedade e da surpresa e os "prazeres da simetria":

Sem a variedade a alma se abate: as coisas que se parecem the surgem como se fossem uma só. [...] Uma uniformidade prolongada torna tudo insuportável [...] é preciso portanto introduzir contrastes nas atitudes. [...] Os contrastes nos surpreendem porque as coisas em oposição se revelam mutuamente [...] A alma gosta da variedade; no entanto, na maioria das coisas ela gosta de encontrar uma espécie de simetria. [...] Uma das principais causas dos prazeres da alma, quando ela vê as coisas, é a facilidade de percebê-las; e a razão pela qual a simetria agrada à alma é que a simetria poupa-Ihe esforços, alivia sua tarefa. [...] Daí decorre uma regra geral: ali onde a simetria é útil à alma e pode ajudála em suas funções, a simetria torna-se agradável; mas onde for inútil, torna-se enfadonha porque elimina a variedade. [A simetria] agrada à alma pela facilidade permitida ao olho de abarcar todo o objeto de uma só vez. Como um objeto que deve ser visto num só golpe de vista precisa ser simples, ele deve ser único e suas partes devem remeter-se ao todo; este é outro motivo pelo qual gostamos da simetria: ela compõe um todo. É da natureza que um todo seja algo completo; e a alma, que vê esse todo, não quer nele encontrar partes imperfeitas. Essa é mais uma razão para apreciar a simetria: o que se exige é uma espécie de ponderação ou equilíbrio: um edifício com uma única ala, ou com uma ala mais curta que a outra, é tão incompleto quanto um corpo com um só braço ou com um braço curto demais (MONTESQUIEU, 2005, p.27-34). 
Mescla-se a essa duradoura fé nos méritos da simetria um entendimento de que, geradas por proporção justa e dotadas de regularidade e auto-equilíbrio, as entidades simétricas são grandezas supostamente plenas, puras, ideia e realidade independentes de pressupostos, histórias e contextos. As entidades simétricas são "acontextuais" (MEYER, 2000, p.259), são entidadesmodelo da tese "da absoluta auto-suficiência do som; auto-suficiência-semântica, auto-suficiência expressiva, auto-suficiência linguística e organizativa" (FUBINI, 1999, p.202). Os ciclos de terceira são então resíduos de um imbróglio que funde e confunde muitas referências, datas e lugares, causas e crenças, feitos e personagens. Trata-se de uma espécie de "harmonia arquetípica", como diz MENEZES (2006, p.34) referindo-se aos construtos harmônicos "culturalmente já guardados na memória auditiva (repertorial) da música ocidental". Trata-se de um composto musical, mas não puramente sonoro, já que conforma "complexos", como diz BRIBITZER-STULL (2006a), valorativos, distintivos e simbólicos.
Com estas considerações gerais, rápidas e parciais, pode-se dizer que, em suma, nas idealizações de uma cultura nacional a música popular ocupa um lugar. Nessa música existe um segmento que se distingue com o rótulo de "música popular brasileira", a "MPB". E dentro deste segmento, ou "campo", se dão disputas simbólicas (cf. CAVALCANTI, 2007). Nestas disputas, em meio a uma alabirintada interação de fatores e efeitos combinados, as estiradas harmonias dos ciclos de terças contribuem na caracterização de uma música plena de "unidade, intensidade e complexidade". Uma música que, neste âmbito popular, massivo e tonal, e dentro de determinados limites históricos, se fez perceber local e internacionalmente como sofisticada, inteligente e cultivada. Uma música afinada com os ideais e façanhas realizadas pelos grandes gênios da arte européia e da música popular do Novo Mundo. Por tudo isso, uma boa música, uma música melhor, mais refinada e mais difícil. Digna, pois, desse seu pertencimento ao rol de produções que se deseja exaltar como "cultura brasileira".

\section{Referências}

ABBAgNANO, Nicola. Dicionário de filosofia. São Paulo: Mestre Jou, 1982.

ABROMONT, Claude e MONTALEMBERT, Eugène de. Teoría de la música: una guía. México: FCE, 2010.

AKE, David Andrew. Jazz cultures. University of California Press, 2002

ALDWELL, Edward e SCHACHTER, Carl. Harmony and voice leading. New York: Harcourt Brace Jovanovich College Publishers, 1989.

ANDRADE, Mário de. Música, doce musica. São Paulo: Livraria Martins Ed., 1963.

BAILEY, Robert (Org.). Richard Wagner: Prelude and Transfiguration from Tristan and Isolde. New York: Norton \& Comp, 1985.

BAIR, Jeff. Cyclic patterns in John Coltrane's melodic vocabulary as influenced by Nicolas Slonimsky's Thesaurus of scales and melodic patterns. University of North Texas, 2003. (Tese de Doutorado).

BARCE, Ramon. Prólogo. In: REGER, Max. Contribuciones al estudio de la modulación. Madrid: Real Musical, 1978.

BASS, Richard. From Gretchen to Tristan: the changing role of harmonic sequences in the nineteenth century. 19thCentury Music, v. 19, n.3, p.263-285, 1996.

BELLEST, Christian e MALSON, Lucien. Jazz. Campinas: Papirus, 1989.

BENT, Ian D. (Ed.). Music analysis in the nineteenth century. Cambridge, University Press, 2004.

BERLINER, Paul F. Thinking in jazz: the infinite art of improvisation. Chicago: The University of Chicago Press, 1994.

BERNSTEIN, David W. Nineteenth-century harmonic theory: the Austro-German legacy. In: CHRISTENSEN, Thomas (Ed.). The Cambridge history of western music theory. Cambridge: Cambridge University Press, 2006. p.778-811.

BERNSTEIN, David W. Symmetry and symmetrical inversion. In: HATCH, Christopher e BERNSTEIN, David W. (Ed.). Music theory and the exploration of the past. Chicago: Chicago University Press, 1993. p.377-407.

BOLING, Mark e COKER, Jerry. The jazz theory workbook. Rottenburg: Advance Music, 1993. 
BRIBITZER-STULL, Matthew. The Ab-C-E complex: the origin and function of chromatic major third collections in nineteenth-century music. Music Theory Spectrum, v.28, p.167-190, 2006a.

BRIBITZER-STULL, Matthew. The end of Die Feen and Wagner's beginnings: An early example of double-tonic complex and associative theme. Music Analysis, n.25, v.3, p.315-340, $2006 \mathrm{~b}$.

BRITO, Brasil Rocha. Bossa Nova. In: CAMPOS, Augusto de. Balanço da bossa: antologia crítica da moderna música popular brasileira. São Paulo: Ed. Perspectiva, 1968. p.17-40.

BROWN, Matthew, DEMPSTER, Douglas e HEADLAM, Dave. The \#IV (bV) hypothesis: testing the limits of Schenker's theory of tonality. Music Theory Spectrum, v.19, n.2, p.155-183, 1997.

CAPLIN, William Earl. Classical form. New York: Oxford University Press, 1998.

CAPUZZO, Guy. Pat Martino's the nature of the guitar: an intersection of jazz theory and neo-riemannian theory. Music Theory Online. v.12, n.1, 2006.

CAVALCANTI, Alberto Roseiro. Música popular: janela espelho entre o Brasil e o mundo. Programa de Pós- Graduação em Sociologia da Universidade de Brasilia, UNB, 2007. (Tese de Doutorado).

CAYMMI, Dori e PINHEIRO, Paulo César. Rio Amazonas [Amazon River], partitura manuscrita, 1991. Disponível em <http:// www.doricaymmi.com/letras.php>. Acesso em: 03 abr. 2012.

CHAFE, Eric Thomas. Analyzing Bach cantatas. New York: Oxford University Press, 2000.

CHRISTENSEN, Thomas. Rameau and musical thought in the enlightenment. Cambridge: Cambridge University Press, 1993.

CINNAMON, Howard. Tonic arpeggiation and successive equal third relations as elements of tonal evolution in the music of Franz Liszt. Music Theory Spectrum, v.8, p.1-24, 1986.

COHN, Richard. Maximally smooth cycles, hexatonic systems, and the analysis of late-romantic triadic progressions. Music Analysis, v.15, n.1, p.9-40, 1996.

COHN, Richard. Weitzmann's regions, my cycles, and douthett's dancing cubes. Music Theory Spectrum, v.22, n.1, p.89$103,2000$.

COKER, Jerry, KNAPP, Bob, e VINCENT, Larry. Hearin' the changes: dealing with unknown tunes by ear. Rottenburg: Advance Music, 1997.

DAHLHAUS, Carl. Studies in the origin of harmonic tonality. Oxford: Princeton University Press, 1990.

DAMSCHRODER, David. Thinking about harmony. Cambridge University Press, 2008.

DARCY, Warren. In search of C major: tonal structure and formal design in act III of Die Meistersinger. In: BRIBITZERSTULL, Matthew, LUBET, Alex e WAGNER Gottfried. Richard Wagner for the new millennium: essays in music and culture. New York: Palgrave Macmillan, 2007. p.111-128.

DELAMONT, Gordon. Modern harmonic technique. Volume 2. Delevan, NY: Kendor Music, 1965.

DEMSEY, David. John Coltrane plays Giant Steps. Milwaukee: Hal Leonard, 1996.

DUDEQUE, Norton E. Harmonia tonal e o conceito de monotonalidade nos escritos de Arnold Schoenberg (1874 - 1951). São Paulo: Escola de Comunicações e Artes da USP, 1997. (Dissertação de Mestrado).

DUDEQUE, Norton E. Music theory and analysis in the writings of Arnold Schoenberg. Aldershot: Ashgate, 2005.

DUNSBY, Jonathan e WHITTALL, Arnold. Análise musical na teoria e na prática. Curitiba: Ed. UFPR, 2011.

FORTE, Allen. The American popular ballad of the golden era 1924-50. Princeton: Princeton University Press, 1995.

FREITAS, Sérgio Paulo Ribeiro de. Que acorde ponho aqui? Harmonia, práticas teóricas e o estudo de planos tonais em música popular. Campinas: Instituto de Artes da Unicamp, 2010. (Tese de Doutorado).

FUBINI, Enrico. Zarlino, Veneza e a música instrumental. Ad Hominem - Revista de Filosofia, Política e Ciência da História, São Paulo, v.1, tomo 2, p.201-211, 1999.

FURTADO FILHO, João Ernani. Samba exaltação: fantasia de um Brasil brasileiro. In: MORAES, José Geraldo Vinci de e SALIBA, Elias Thomé (Orgs.). História e Música no Brasil. São Paulo: Alameda: 2010. p.269-318.

GAULDIN, Robert. La práctica armónica en la música tonal. Madrid: Ed. Akal, 2009.

GAULDIN, Robert. Tracing Mathilde's Ab major. In: BRIBITZER-STULL, Matthew, LUBET, Alex e WAGNER Gottfried. Richard Wagner for the new millennium: essays in music and culture. New York: Palgrave Macmillan, 2007. p.27-42.

GOLLIN, Edward Henry. Representations of space and conceptions of distance in transformational music theories. PhD, Harvard University, 2000.

GUEST, lan. Harmonia, método prático. v.2. Rio de Janeiro: Lumiar, 2006.

HARRISON, Daniel. Harmonic function in chromatic music. Chicago, University of Chicago Press, 1994.

HAUPTMANN, Moritz. The nature of harmony and metre. London: Swan Sonnenschein, 1888.

HERRERA, Enric. Teoria musical y armonia moderna, volume II. Barcelona: Antoni Bosch, 1995.

JAFFE, Andrew. Jazz harmony. Advance Music, 1996.

JAVIER, Ramirez Miguel. Analytic approaches to the music of Anton Bruckner: Chromatic third-relations in selected late compositions. Ph.D., The University of Chicago, 2009. 
KARG-ELERT, Sigfrid. Precepts on the polarity of sound and tonality. The logic of harmony. Victoria: Harold Fabrikant, 2007.

KINDERMAN, William e KREBS, Harald. The second practice of nineteenth-century tonality. Lincoln: University of Nebraska Press, 1996.

KOBBÉ, Gustave. O livro completo da Ópera. Rio de Janeiro: Zahar Ed., 1991.

KOPP, David. Chromatic transformations in nineteenth-century music. Cambridge: Cambridge University Press, 2002.

KREBS, Harald. Third relation and dominant in late 18th-and early 19th-century music. Ph.D. dissertation, Yale University, 1980.

KUEHN, Frank Michael Carlos. Antonio Carlos Jobim, a Sinfonia do Rio de Janeiro e a Bossa Nova: caminho para a construção de uma nova linguagem musical. Rio de Janeiro: Universidade Federal do Rio de Janeiro, UFRJ, 2004 (Dissertação de Mestrado).

KUNZE, Stefan. Las óperas de Mozart. Madrid: Alianza Ed., 1990.

KURTH, Ernst. Romantische Harmonik und ihre Krise in Wagners Tristan. Hildesheim: G. Olms, 2005.

LA MOTTE, Diether de. Armonía. Barcelona: Editorial Labor, 1993.

LA VERNE, Andy. Twelve Steps to Giant Steps. Keyboard, p.56-75, November 1996.

LERDAHL, Fred. Tonal pitch space. New York: Oxford University Press, 2001.

LEVINE, Mark. The jazz theory book. Petaluma, CA: Sher Music Co., 1995.

LOBO, Edu. Songbook Edu Lobo. Rio de Janeiro: Lumiar Editora, 1994.

LOCKWOOD, Lewis. Beethoven:a música e a vida. São Paulo: Códex, 2004.

MANGUEIRA, Bruno Rosas. Concepções estilísticas de Hélio Delmiro: violão e guitarra na música instrumental brasileira. Universidade Estadual de Campinas, 2006. (Dissertação de Mestrado em Música).

MARTIN, Henry. Charlie Parker and thematic improvisation. Institute of Jazz Studies Rutgers - The State University of New Jersey, 1996.

MARVIN, William. Subverting the conventions of number opera from within: hierarchical and associational uses of tonality in act I of Der fliegende Holländer. In: BRIBITZER-STULL, Matthew, LUBET, Alex e WAGNER, Gottfried. Richard Wagner for the new millennium. New York: Palgrave Macmillan, 2007. p.71-90.

MENEZES, Flo. Apoteose de Schoenberg: tratado sobre as entidades harmônicas. São Paulo: Ateliê Ed., 2002.

MENEZES, Flo. Música maximalista: ensaio sobre a música radical e especulativa. São Paulo: Ed. UNESP, 2006.

MEYER, Leonard B. El estilo en la música. Teoria musical, história e ideologia. Madrid: Pirámide, 2000.

MILLINGTON, Barry (Org.). Wagner um compêndio. Rio de Janeiro: Zahar, 1995.

MODIRZADEH, Hafez. Aural archetypes and cyclic perspectives in the work of John Coltrane and ancient chinese music theory. Black Music Research Journal, v.21, n.1, p.75-106, 2001.

MONTESOUIEU, Charles de Secondat, Baron de. 0 gosto. São Paulo: Iluminuras, 2005.

MORGAN, Robert . Dissonant prolongation: theoretical and compositional precedents. Journal of Music Theory, v.20, n.1, p.49-91, 1976.

NASCIMENTO, Hermilson Garcia do. Recriaturas de Cyro Pereira: arranjo e interpoética na música popular. Campinas: Universidade Estadual de Campinas, Instituto de Artes, 2008. (Tese de Doutorado).

NATTIEZ, Jean-Jacques. 0 desconforto da musicologia. Per Musi, Belo Horizonte, n.11, p.5-18, 2005.

NETTLES, Barrie e GRAF, Richard. The chord scale theory \& jazz harmony. Advance Music, 1997.

OTMAN, Robert. Advanced harmony: theory and practice. Upper Saddle River, NJ: Prentice Hall, 2000.

PISTON, Walter. Armonia. Barcelona: Labor, 1993.

POLETTO, Fábio Guilherme. Tom Jobim e a modernidade musical brasileira 1953-1958. Universidade Federal do Paraná, 2004. (Dissertação de Mestrado).

PORTER, Lewis. John Coltrane: His life and music. Ann Arbor: University of Michigan Press, 1999.

PROCTOR, Gregory Michael. Technical bases of nineteenth-century chromatic tonality: A study in chromaticism. Ph.D., Theory, Princeton University, 1978.

RATNER, Leonard G. Romantic music: sound and syntax. New York: Schirmer Books, 1992.

RAWLINS, Robert e BAHHA, Nor Eddine. Jazzology: the encyclopedia of jazz theory for all musicians. Milwaukee, WI: Hal Leonard, 2005.

REHDING, Alexander. Hugo Riemann and the birth of modern musical thought. Cambridge: Cambridge University Press, 2008.

RIBEIRO JR., Wilson Alves (Ed.). Hinos homéricos: tradução, notas e estudo. São Paulo: Ed. UNESP, 2010.

RIEMANN, Hugo. Dictionary of music. London: Augener, 1908.

RIMSKY-KORSAKOV, Nicolas. Tratado prático de armonía. Buenos Aires: Ricord, 1946.

ROSEN, Charles. A geração romântica. São Paulo: Edusp, 2000. 
RUSSEL, George. The lydian chromatic concept of tonal organization. The art and science of tonal gravity. Brookline, Massachusetts: Concept Publishing Company, 2001.

SALZER, Felix e SHACHTER, Carl. El contrapunto en la composición: el estudio de la conducción de las voces. Barcelona: Idea Books, 1999.

SASLAW, Janna K. Gottfried Weber and the concept of Mehrdeutigkeit. Columbia University, 1992.

SCHENKER, Heinrich. Tratado de armonia. Madrid: Real Musical, 1990.

SCHENKER, Heinrich. Der freie Satz III (anhang: figurentafeln). Wien: Universal Edition, 1956.

SCHOENBERG, Arnold. El estilo y la idea. Barcelona: Idea Books, 2005.

SCHOENBERG, Arnold. Funções estruturais da harmonia. São Paulo: Via Lettera, 2004.

SCHOENBERG, Arnold. Fundamentos da composição musical. São Paulo: Edusp, 1991.

SCHOENBERG, Arnold. Harmonia. São Paulo: Ed. da Unesp, 2001.

SCHUSTER-CRAIG, John. The major-third system in late-nineteenth and early-twentieth-century russian harmonic practice. In: ANNUAL MEETING, SOCIETY FOR MUSIC THEORY, 22., 1999, Atlanta. Anais... Atlanta, 1999.

SCRUTON, Roger. The aesthetics of music. Oxford University Press, 1999.

SECHTER, Simon. Die Grundsätze der musikalischen Komposition. Erste abtheilung: Die richtige folge der grundharmonien, oler vom fundamentalbass und dessen umkehrungen und stellvertretern. Leipzig: Druck und Verlag von Breitkopf und Härtel, 1853.

SHIRLAW, Matthew. The theory of harmony: an inquiry into the natural principles of harmony, with an examination of the chief systems of harmony from Rameau to the present day. New York: Da Capo Press, 1969.

SHUKER, Roy. Vocabulário de música pop. São Paulo: Hedra, 1999.

SLONIMSKY, Nicolas. Thesaurus of scales and melodic patterns. New York: Amsco Publications, 1975.

SOARES, Astréia. Outras conversas sobre os jeitos do Brasil: o nacionalismo na música popular. São Paulo: Annablume, 2002.

SOLEIL, Jean-Jacques e LELONG, Guy. As obras-primas da música. São Paulo: Martins Fontes, 1992.

SOMER, Avo. Chromatic third-relations and tonal structure in the songs of Debussy. Music Theory Spectrum, v. 17, n.2, p.215-241, 1995.

STRUNK, Steven. Chick Corea's 1984 performance of "Night and Day". Journal of Music Theory, v. 43, n.2, p.257-281, autumn, 1999.

STRUNK, Steven. Harmony (i). In: KERNFELD Barry (Ed). The New Grove Dictionary of Jazz. Grove Music Online. Oxford Music Online. 2008.

TARASTI, Eero. Signs of music: a guide to musical semiotics. Berlin: Mouton de Gruyter, 2002

TARUSKIN, Richard. Chernomor to Kashchei: harmonic sorcery; or, Stravinsky's "angle". Journal of the American Musicological Society, v.38, n.1, p.72-142, 1985.

TARUSKIN, Richard. Stravinsky and the russian traditions. Berkeley: University of California Press, 1996.

TATARKIEWICZ, Wladyslaw. Historia de seis ideas: arte, belleza, forma, creatividad, mímesis, experiencia estética. Madrid: Editorial Tecnos, 2002.

TODD, Larry. The "unwelcome guest" regaled: Franz Liszt and the augmented triad. 19th-Century Music, v. 12, n.2, Special Liszt Issue, p.93-115, 1988.

WASON, Robert W. Viennese harmonic theory from Albrechtsberger to Schenker and Schoenberg. Rochester, NY: University of Rochester Press, 1995.

WEISKOPF, Walt e RICKER, Ramon. Coltrane: a player's guide to his harmony. New Albany: Aebersold, 1991.

WISNIK, José Miguel. A paixão dionisíaca em Tristão e Isolda. In: CARDOSO, Sérgio... (et al). Os sentidos da paixão. São Paulo: Companhia das Letras, 1987. p.195-227.

\section{Notas}

1 Sobre a hipótese de que, um estudo do célebre conceito wagneriano de obra de arte total ou integral (Gesamtkunstwerk) pode ser contributivo na avaliação crítica das "funções dos acordes" nas análises da música popular, ver FREITAS (2010, p.750).

2 Pela singularidade do engenho, vale mencionar mais uma canção que, também contando com os efeitos do ciclo de terças menores, estabelece outra espécie de contraponto com o prazeroso "quero morrer..." do Hino ao Sol e o doloroso "morrer de amor" de Wagner. Trata-se de Viver do Amor de Chico Buarque, uma das canções da exitosa Ópera do Malandro escrita entre 1977 e 1978. Embora neste caso não seja possivel estabelecer correlações diretas entre texto e música, nos 16 compassos do segmento instrumental que ouvimos na introdução e na coda da versão em disco (Ópera do Malandro, Polygram/Philips, 1979), que conta com o arranjo de Francis Hime, reencontramos o ciclo F7M $\rightarrow$ D7M $\rightarrow B 7 M \rightarrow A b \rightarrow F$ ambientando quatro repetições da mesma frase melódica que, logo no primeiro verso, "prá se viver o amor", vamos reouvir na voz da atriz e cantora Marlene.

3 Em linhas gerais, pode-se notar que esta noção de "multitonic system" da jazz theory guarda correlações com a noção que, no campo acadêmico, é conhecida como "tonal pairing". Um "emparelhamento" ou "equiparação tonal" que, por sua vez, amplia as capacidades do dispositivo analítico que Bailey chamou de "double-tonic complex" (cf. BRIBITZER-STULL, 2006b, p.323-325; DUDEQUE, 2005, p.124; KINDERMAN e KREBS, 1996, p.17-18). 
4 Conforme BRIBITZER-STULL (2006b, p.322), "tonalidade associativa" ("associative tonality") é um conceito dramático-tonal elaborado por BAILEY (1985) no ensejo de suas análises da música de Wagner. Trata-se de "um tipo de tonalidade referencial na qual um uma área tonal específica (p.ex., a tônica Réb Maior), uma sonoridade (p.ex., a tétrade meio-diminuta), ou uma função tonal (p.ex., a Napolitana) são consistentemente associadas a um elemento dramático específico". Alguns estudos que abordam questões de "tonalidade associativa" são: DARCY (2007), FREITAS (2011, p.412415), GAULDIN (2007), LERDAHL (2001, p.133), MARVIN (2007) e MILLINGTON (1995, p.323-324 e 478).

5 Como se sabe, Schoenberg abordou tais assuntos (da variedade desproporcionada, do desvalor da repetição simples, das trucagens harmônicas apelativas, do valor estético, filosófico e humanista da compreensibilidade, da distinção entre "sequência" e "variação da sequência" etc.) em várias oportunidades (cf. SCHOENBERG, 2005, p.63-169; 2004, p.148-160). No caso do estudo das "músicas nacionais", vale também levar em conta o fato igualmente conhecido de que, de modo geral, estas "sequências" (wagnerianas ou outras) associadas a estes planos tonais embasados em ciclos de terças (na música de Schubert, Liszt, Chopin, Wagner, Brahms, Rimsky-Korsakov, Glinka, etc.), tomaram parte de diferentes programas nacionalistas. Idealizações sofisticadas que, de forma geral, são referidas como "nacionalismo romântico" (cf. TARUSKIN, 1996, p.261-262).

6 Sobre a temática Giant Steps ver: AKE (2002, p.129-134), BAIR (2003, p.3-5), BELLEST e MALSON (1989, p.112-114), BERLINER (1994, p.80, 232233), CAPUZZO (2006, p.11-14), COKER, KNAPP e VINCENT (1997, p.25-28), DEMSEY (1996), HERRERA (1995, p.117-121), JAFFE (1996, p.167-169), LA VERNE (1996), LEVINE (1995, p.351-379), MANGUEIRA (2006, p.69-72), MARTIN (1996, p.10-13), MODIRZADEH (2001), NETTLES e GRAF (1997, p.163-165), PORTER (1999, p.145-158), RUSSEL (2001, p.95-99), STRUNK (2008), WEISKOPF e RICKER (1991).

7 À margem, é oportuno observar uma espécie de tênue associação que, aos poucos, vai se construindo entre canções complexas, célebres parcerias da MPB, ciclos de terceira e o nome de Tom Jobim. Sobre o Choro Bandido, em diferentes oportunidades Edu Lobo já declarou que a canção tem a "cara do Tom" e, como se sabe, a canção foi dedicada a Jobim. Dez anos depois, em 1995, Chico e Caetano se reencontram em Como um Samba de Adeus, uma canção de despedida dedicada a Jobim (falecido em dezembro de 1994) que, com arranjo de Jaques Morelenbaum, foi gravada por Gal Costa em seu álbum Mina d'Água do Meu Canto (RCA/BMG, 1995). Nos versos centrais desta canção, em Sol-maior, reencontramos o complexo $\mathrm{B} 7 \mathrm{M} \rightarrow \mathrm{Eb} 7 \mathrm{M} \rightarrow \mathrm{G} 7 \mathrm{M}$ ambientando os versos "Como nunca mais, eu penso / Como um samba de adeus / Com que jeito acenar o meu lenço branco...".

Sérgio Paulo Ribeiro de Freitas (1962-) é professor na Universidade do Estado de Santa Catarina (UDESC, Florianópolis) e membro dos grupos de pesquisa "Processos músico-instrumentais" (UDESC) e "Música Popular: história, produção e linguagem" (UNICAMP). É Doutor em música pela Universidade Estadual de Campinas (cf. FREITAS, 2010) e atua nas áreas de teoria, análise musical, contraponto, arranjo e harmonia tonal. Atualmente desenvolve a pesquisa "Para tudo na vida tem um acorde: da persistência das ideias românticas na apreciação valorativa da música popular" (PROPPG, UDESC). 